This version is close to the final one published.

For citations: Ergas, O. and Hadar, L. L. (2019). Mindfulness in and as education: a map of a developing academic discourse from 2002 to 2017, Review of Education.

\title{
Mindfulness In and As Education: \\ A Map of a Developing Academic Discourse from 2002 to 2017
}

Oren Ergas and Linor L. Hadar, Faculty of Education, Beit Berl College.

\begin{abstract}
Since the turn of the millennium there has been a clear rise in the implementation and research of mindfulness across primary, secondary and postsecondary education. These implementations, however, hardly constitute a uniform phenomenon. They reflect a variety of framings, modalities and educational aims, as documented in hundreds of peer-reviewed papers. To date no overarching review has provided an empirically-based mapping of this multifaceted and rapidly developing discourse. This paper offers a first-of-its-kind map of mindfulness in education based on the 447 peer-reviewed papers published between 2002 and 2017 that constitute this academic discourse, applying grounded theory methodology. The research reveals an exponential rise in the amount of publications over years, with a complex discourse that evolves from seven different framings of the practice, applied to nine different educational domains and through various types of implementation. It maps this complexity and outlines two main patterns that reflects this discourse to date: a) Mindfulness in education, which comprises mostly of outsourced, secularized interventions aimed at improved mental-physical health, social-emotional learning and cognitive functions. b) Mindfulness as education, which is a more transformative strand characterized by contemplative pedagogy in higher education and sporadic whole-school implementations. Overall, in the studied period mindfulness has been moving from near-anonymity toward the mainstream; however, this discourse reflects a nascent phase given that it is only beginning to critique itself. Furthermore, its two patterns reflect a split discourse that is challenged by the practice's psychological-secular framing and its Buddhist framing.
\end{abstract}

Keywords: mindfulness in education, curriculum, implementation, grounded theory. 


\section{Mindfulness In and As Education: A Map of a Developing Academic Discourse from}

\section{2 to 2017}

In the past two decades, the practice of mindfulness - "paying attention, on purpose, in the present moment, non-judgmentally" (Kabat-Zinn, 1994, p. 4) - has become ubiquitous. Studies of its effects on various aspects of psychological well-being and health have spurred the interest of the scientific community leading to an exponential rise in its implementation, research and critique (Brown, Craswell, \& Ryan, 2015; Purser, Forbes, \& Burke, 2016; Schonert-Reichl \& Roeser, 2016). The American Mindfulness Research Association (AMRA) documented over 3700 studies published on mindfulness reflecting an exponential rise from 0 publications in 1980 to 690 in 2016 and 692 in 2017 (Black, 2018). Many of these studies have been funded by the National Institute of Health $(\mathrm{NIH})$ and demonstrated effects of mindfulness on improved well-being, stress-reduction, and enhanced attention regulation, within both clinical and general populations (Brown et al, 2015; Keng, Smoski \& Robins, 2011; Zoogman, Goldberg, Hoyt, \& Miller, 2015).

Parallel to and as part of these development, there has been a clear rise in the implementation and study of mindfulness across ages within educational settings, as documented in several peer-reviewed studies, reviews and special issues (Felver \& Jennings, 2016; Frank, Jennings \& Greenberg, 2013; Kiloran, 2017; Meiklejohn et al, 2012; Moreno, 2017; Renshaw \& Cook, 2017; Roeser, 2014; Schonert-Reichl \& Roeser, 2016; Weare, 2013; Zenner, Herrnleben \& Wallach, 2014). Key organizations, such as the Mindfulness in Schools Project (MiSP) in UK, and MINDUP in the US, have been developing mindfulness curricula, training school teachers and disseminating these practices in hundreds of schools worldwide (Kuyken et al, 2013; Maloney, Lawlor, Schonert-Reichl, \& Whitehead, 2016). According to reviews and to some of these mentioned organizations, these curricula have reached thousands of teachers and millions of students spanning all ages (Ergas, 2018; 
Semple, Droutman \& Reid, 2017). Research of mindfulness in education has now expanded to huge state-funded projects, such as the Oxford Mindfulness Center's MYRIAD, which includes 84 UK schools (approx. 6000 students).

The term "mindfulness in education", however, hides a perplexing diversity that a deeper scrutiny of publications in this field demonstrates. To begin with, many of the above initiatives involve mindfulness-based interventions (MBIs) - outsourced programs developed based on Jon Kabat Zinn's mindfulness-based stress reduction (MBSR) format, and adapted for teachers and/or students (Cullen, 2011; Jennings et al, 2017; Kabat Zinn, 2017; Roeser, 2014). However, implementations of mindfulness practice in education have also been developing within "contemplative pedagogy" (Ergas, 2018; Repetti, 2010). Here mindfulness is integrated into teaching in order to enhance meaningful and transformative learning processes often in higher education and within education in the professions (Bush, 2011; Magee, 2016). When examining publication in these two domains one finds that mindfulness is implemented across educational settings based on highly diverse modalities, definitions, framings, and aims. This diversity begins with the practice itself, which is framed in variety of ways, such as attentional training, mental training, meta-cognitive practice, spiritual practice, meditation, Buddhist meditation, and contemplative inquiry (Bishop et al, 2004; Davidson et al., 2012; Hanh, 2016; Kabat-Zinn, 1994; Owen-Smith, 2017; Roeser, 2014; Roth, 2006, Shapiro et al., 2015; Wong, 2004). These latter terms and others are sometimes associated with a psychological discourse (Kabat-Zinn, 1994), at other times with the practice's Buddhist or other wisdom-tradition origins (Hoyt, 2016), and yet at other times with a way of knowing-inquiring (Hart, 2004; Roth, 2006). When further probing the psychological discourse, one finds some MBIs associated with cognitive functions (e.g., Flook et al, 2010), others with the affective and social-emotional domain (e.g., Beddoe \& 
Murphy, 2004), and yet others with mental-physical and occupational health (e.g., Crain, Schonert-Reichl \& Roeser, 2017).

The complexity in this discourse further manifests in implementations that span interventions that are as short as four sessions (Zenner et al., 2014) to holistic approaches integrating mindfulness across the curriculum (Tarrasch et al., 2017). Yet, the most perplexing domain that manifests the breadth and diversity in this discourse concerns how they are associated with educational aims. Pointing to a mere few examples, one finds MBIs addressing teacher stress, burnout and social-emotional competencies (Jennings et al, 2017), enhancement of executive functions in primary school (Flook et al, 2010), improving Graduate Record Examinations (GRE) performance (Mrazek et al, 2013), but also contemplative pedagogies that aim to cultivate self-knowledge and awareness (Holland, 2004), a first-person critical perspective (Roth, 2006), and ethics of diversity (Berila, 2014). Professional education reveals additional avenues with higher education courses in which mindfulness is implemented toward cultivating empathy in training nurses (Beddoe \& Murphy, 2004), spirituality and compassion in social work education (Wong, 2004), reducing cognitive and emotional biases in law students (Magee, 2016), and engendering healthy habits of mind and compassion in teaching (Roeser, Skinner, Beers, Jennings, 2012).

The above is a very rough gloss over what appears to be a highly complex and confusing discourse. Mindfulness in education is developing in multiple directions to the point at which it becomes unclear what holds this discourse together and, in fact whether this is one discourse at all? How is it possible that a practice (or set of practices) that goes by the same name is responsible for all of these aims, some of which seem to be pulling in almost contradicting directions? Where is mindfulness in education going?

One potential explanation for the variety described emerges from the multiple framings of this practice mentioned above. Mindfulness has a unique biography that begins in 
the 6-5th centuries BC within Buddhism, yet in the late 20th century it was reframed as a psychological-clinical and secularized practice (Gethin, 2011; Kabat-Zinn, 1994; Olendzki, 2011; Purser et al, 2016; Roeser, 2013). However, this only leads to further questions. What is a practice that has its origins in Buddhism doing in contemporary public schools; especially when this occurs in countries such as the US that stress the separation of Church and State? How secular/religious is this discourse? Indeed, there have been lawsuits filed against schools who implemented the practice, accusing them of proselytizing Buddhism to students (Gregoire, 2013; Parker, 2018). Sensitive to this issue, implementers of mindfulness have hence often been grounding the practice in scientific-psychological constructs and avoiding Buddhist terminology (Jennings, 2016; Nelson, 2012). However, this trend has lead to other types of critique often referred to as 'McMindfulness', revolving around the commodification of mindfulness, its uprooting from its ethical underpinnings and its construal as a panacea (Forbes, 2019; Hyland, 2017; Purser \& Loy, 2013). Scientists themselves have been warning against the "hype" around mindfulness that reflects an enthusiasm that the present state of research does not justify (Greenberg \& Harris, 2012; Van dam et al., 2018).

These and other challenging perspectives, in fact reflect an additional strand within the general discourse of mindfulness and within mindfulness in education. It is comprised of critical perspectives that point to the ways in which social, political, cultural and economic forces shape mindfulness as it enters educational settings (Purser et al, 2016). Taking the above introduction and these critical perspectives, we are facing a situation in which a practice that in the course of approximately two decades, has transitioned from nearanonymity and an association with monks, spiritual seekers and ancient times, to a vibrant academic discourse that seems to be moving into the mainstream of education. This is happening in an extremely rapid pace and in multiple ways that are becoming difficult to understand. Such situation calls us to question what is this novel addition to the curriculum 
bringing into contemporary education? Is it introducing religiosity/spirituality in disguise? Is it a technique for reducing stress? Is it about improving academic achievements? Is it about all of these? Is it the same phenomenon in primary education as it is in higher education?

The current research responds to this confusion by developing a first-of-its-kind empirically-based map of the discourse of mindfulness in education. To the best of our knowledge, no previous review that takes into consideration all manifestations of this field has been offered. Previous reviews in this field usually relied on relatively small numbers of cases and focused either on MBIs or on contemplative pedagogies, either centering around their effects or on their ways of implementation (e.g., Bush, 2011; Lomas et al., 2017; Meiklejohn et al., 2012; Moreno, 2017; Zenner et al.'s, 2014). While no doubt necessary and informative, such reviews fail to provide a map of the entire discourse and its development as a whole. The current research is hence not a review of the effects of the practice, neither a paper that advocates or critiques its implementation in education. It is about understanding what is going on? What has been published in this field? What kind of voices are emerging in it? What are the main characteristics of this discourse and is it one discourse or many? Specifically, we aim to (a) map the discourse, the aims and framings of mindfulness across public and secular educational settings. (b) Investigate to what extent is mindfulness in education a spiritual/religious/Buddhist practice. (c) Map curricular patterns and types of implementations of mindfulness in these settings. (d) Identify developed and underdeveloped domains within the discourse and suggest future directions.

The map that this research aims to develop has both theoretical and practical significance. It enables for a broader conception of the various directions that this discourse entails and their respective breadth, robustness and/or weakness. This expands limited understandings of mindfulness in education by taking into consideration multiple components of this discourse (e.g., types of research, framings of mindfulness, modalities of 
implementation) and enables those working in the field to locate their work within it in more sophisticated and nuanced ways. Finally, it points us to neglected theoretical and practical domains and hence opens the field for further development.

\section{Method}

\section{Definition of the Review Project: Need, Aim and Orientation}

The current project proposes a conceptual systematic review and mapping of the diverse strands and voices within the discourse of mindfulness in education. We see the essential tasks of this synthesis as integrating major aspects and themes found in the literature into a higher-order structure (Dixon-woods, 2005, Wolgemuth, Hicks \& Agosto, 2017). Expanding the scope of previous reviews that focused on limited domains, our aim is to include all domains of implementation and conceptualization of mindfulness in education within one mapping of the field. Our emphasis is on providing an inclusive understanding of mindfulness in education, such that expresses and charts the diversity of this discourse. We do not focus on whether mindfulness is effective and hence should or should not be implemented, but rather provide a map of the ways in which it is treated and implemented in the field. Our inclusive approach aims to chart this discourse and its development in an interpretive manner that stems from and leads toward a more grounded understanding of what is currently happening in the field as it emerges from research.

\section{Search and Selection Process}

The current review explored the academic discourse that has developed between 2002 and 2017. Peer-reviewed papers published in this period served as its primary source of data. The starting point of 2002 was established based on Schonert-Reichl and Roeser's (2016) charting of peer-reviewed publications in the field, revealing very scarce publications in the 
domain of mindfulness in education prior to this year; as was also confirmed by our own searches. In order to find and select the papers for this review we followed these steps:

\section{Systematic search.}

In order to represent the diversity of curricular voices outlined above we began with a systematic literature search (Petticrew \& Roberts, 2008, Wolgemuth et al., 2017). To find relevant articles, we conducted electronic searches using the following search engines: Sciencedirect, Google scholar and EBSCO host (which includes PubMed, PsychINFO, and ERIC). We used several cross-searches of the term mindfulness combined with various terms associated with education (e.g., education, students, school, teachers, higher education, professional education). In addition, to these electronic searches we conducted auxiliary manual searches in the American Mindfulness Research Association's (AMRA) monthly reviews, which list peer-reviewed publications on mindfulness. Reference lists of key review publications found in our searches were also scrutinized to uncover additional publications.

\section{Criteria for inclusion/exclusion.}

Given the above mentioned MBI and contemplative pedagogy review strands and the lack of meta-approaches to the discourse as a whole, our methodology was guided by a systematic review approach (Wolgemuth et al., 2017). This applied first to the formulation of inclusion and exclusion criteria, which comprised of two stages. In June 2017 we conducted a first broad search that was limited to:

1. Peer-reviewed full papers in English: This excluded papers published in non-peerreviewed journals, brief reports and book reviews.

2. The period of 2002 to June 2017: At this point we uncovered 450 publications. 
We read publication titles, abstracts and at times full papers that we found in our searches. Publications were included in the database if they complied with all of the following criteria (number of excluded publications appear in brackets):

3. Focused on mindfulness as a meditative practice: Following previous reviews, papers were included only if they applied the term mindfulness to at least one variation of the following practices: body scan, focused attention, open monitoring, kindness practices, mindful movement (Roeser, 2014; Zenner et al, 2014). The concept of mindfulness has become known in the context of learning based on Ellen Langer's work, which does not frame it as a meditation practice (Langer \& Moldoveanu, 2000). Hence, studies that referred to Langer's conception were included only if this was an auxiliary framing added to its framing as a meditative practice. We excluded papers that involved implementation of yoga, tai chi or meditation if these were not accompanied specifically with mindfulness practice. We also excluded papers that merely mentioned mindfulness on passing, without providing at least minimal details from which the presence of the above mentioned mindfulness practices could be detected (30).

4. Implemented mindfulness with students/teachers/educators/faculty in educational settings: We excluded publications that included students/teachers only as their study population and did not frame their aim in educational terms (e.g., referring to the practice as enhancing creativity or problem-solving without arguing how and why the latter contribute to education) (9).

5. Implemented mindfulness with non-clinical populations: studies involving mental or health disorders (e.g., diabetes) were excluded; however, counselling in school and students with learning disabilities (e.g., ADHD) in school settings were included (26). 
After the initial search and the development of the in/exclusion criteria, the researchers met several times to decide, which of these publications would be included in the review. Each of the 450 publications was judged against the criteria for inclusion. In case of disagreement, the researchers discussed the article until 100\% agreement was reached. After this phase we prepared a list that included the 385 papers retained after this process.

In order to make sure that all papers meeting these criteria were identified, and in order to be able to include papers that were published up until December 31, 2017, in March 2018 we returned to the search engines for a second search. We also scanned reference lists of review studies and special issues found in our previous search to further enhance the inclusivity of our searches. 62 additional publications, which meet our criteria, were found. Overall this search process yielded 447 papers that were included in our data.

\section{Summarizing the Studies.}

Following suggestions put forth by Petticrew and Roberts (2008), a table summarizing each paper was created. This table listed each paper's characteristics including: the title and authors of the paper, the paper's publication date, and the name of the journal in which it was published. The table allowed for a critical appraisal of the papers included and ensured the flagging of duplicate listings (Table S1, online only).

\section{Developing the Coding System and Analysis Procedures}

In accordance with our aim to map the mindfulness in education field in an inclusive way, we chose to use grounded theory methodology to guide our coding and analysis process (Glaser \& Strauss, 1967). Grounded theory is considered a sound approach to the synthesis of studies in systematic reviews (Dixon-woods, 2005). The constant comparative method, the most widely used element of grounded theory, had the most obvious potential for application because it offered a set of procedures by which data may be analysed (Dixon-woods, 2005). 
Grounded theory is applied in the social sciences as a method for deriving theories inductively based on garnering data from the field. It is especially useful in cases of complex social phenomena, such as mindfulness in education, which as we introduced, is diversely framed and interpreted. As typical in such research, our use of grounded theory entailed an interplay between data collection and analysis (Corbin \& Strauss, 1990), which enabled controlling, defining and redefining the scope and nature of the phenomenon studied as part of the process of the research (Charmaz, 2006). In order to interpret the discourse of mindfulness in education all publications selected for this study were read and the coding system was developed using the following steps:

\section{Open coding - the development of the initial coding system.}

Reading the publications, we inductively identified categories based on open coding (Glaser \& Strauss, 1967). As in grounded theory procedures some background assumptions alerted us to certain possibilities in the data (Charmaz, 2006). Thus, the open coding phase was based on a dual procedure: bottom-up in which the publications informed the construction of the initial categories, and top-down, in which our background knowledge of the field informed the construction of the categories. Hence questions concerning who, when, what, why? based on familiarity with mindfulness in education, provided scaffolds for potential categories. Initially, these questions included: What is the conceptualization provided in the paper for mindfulness in education? What is the aim of the paper? What implications for educational theory and practice does the paper offer? The dual process yielded additional questions including: What is the framing of mindfulness practice? What effects does the paper attribute to mindfulness? How is mindfulness incorporated into the curriculum? What is the reported intensity of implementation? And what are the characteristics of the population to which mindfulness is offered in the paper? 
With these questions in mind we open coded 150 papers and developed an initial set of organizing themes. A set of categories for each organizing theme was also developed at this stage. Table S2 (online only) presents a full list of the organizing themes and codings. This phase entailed reading, coding and categorizing based on a constant comparison method until arrival at saturation; that is, a stable and comprehensive set of organizing themes and categories that capture the phenomenon, with no variations challenging it (Glaser \& Strauss, 1967).

At a second stage, in order to ensure the trustworthiness of the coding, validate the clarity of the organizing themes and initial categories, and verify the covering of nuances of the phenomenon, 10 identical papers were coded independently by each of the two researchers. Results were compared, discrepancies were discussed, and changes were introduced into the coding system. Five additional papers were then coded arriving at $100 \%$ agreement.

At a third stage we coded the remaining papers. Overall, 447 papers were coded using Microsoft Excel software listing each paper by title, author(s), and year of publication, followed by at least one column for each organizing theme. Some categories included more than one column as some publications addressed more than one category (e.g., papers including both students and teachers as population group in which case the two groups were coded in two separate columns). Papers were only coded for the categories that applied to them.

\section{Development of the final coding system.}

In the initial coding, each organizing theme included multiple codings (ranging from 4 to 91 ). Therefore, this phase of analysis included a process in which we grouped the categories within each organizing theme to create the final coding scheme. This grouping process was also based on grounded theory secondary category analysis, similarly aimed at 
reaching a stable and comprehensive set of categories that capture the phenomenon (Glaser \& Strauss, 1967). Trustworthiness was obtained by grouping of the initial categories by each of the researchers independently, followed by comparison and revision to achieve agreement.

Table 1 provides the final organizing themes and corresponding categories accompanied by a brief elaboration of some of the more complex categorizations.

Table 1: Final Coding Scheme

\begin{tabular}{|c|c|c|}
\hline $\begin{array}{l}\text { Organizing themes } \\
\text { and their definition }\end{array}$ & $\begin{array}{l}\text { Some methodological } \\
\text { considerations and } \\
\text { aims of organizing } \\
\text { theme }\end{array}$ & $\begin{array}{l}\text { Categories. Includes an example of paper that } \\
\text { falls in each category in brackets. }\end{array}$ \\
\hline $\begin{array}{l}\text { Type of paper - } \\
\text { distinguishes } \\
\text { between field } \\
\text { research and } \\
\text { implementations, } \\
\text { reviews and } \\
\text { conceptual papers in } \\
\text { the field. }\end{array}$ & $\begin{array}{l}\text { Provides a general } \\
\text { overview of field- } \\
\text { based and oriented } \\
\text { research compared to } \\
\text { conceptual papers. }\end{array}$ & $\begin{array}{l}\text { - Field research or implementation (empirical } \\
\text { studies of mindfulness-based interventions } \\
\text { (Ancona \& Mendelson, 2014) and self- } \\
\text { narratives of lecturers/teachers implementing } \\
\text { mindfulness in higher education (Holland, } \\
\text { 2004)). } \\
\text { - } \\
\text { - } \\
\text { Ceviews/meta-analyses (Zenner et al, 2014) }\end{array}$ \\
\hline $\begin{array}{l}\text { Type of research - } \\
\text { offers a distinction } \\
\text { in terms of the } \\
\text { perspective from } \\
\text { which papers are } \\
\text { written. }\end{array}$ & $\begin{array}{l}\text { Provides a finer } \\
\text { resolution of the } \\
\text { previous category to } \\
\text { enable distinctions } \\
\text { within field-based and } \\
\text { oriented research. } \\
\text { Conceptual papers } \\
\text { coded } 3 \text { for type were } \\
\text { coded here } 3 \text { as well) }\end{array}$ & $\begin{array}{l}\text { - Empirical (Jennings et al, 2017) } \\
\text { - Personal-narrative/self-studies (Holland, } \\
\text { 2004) } \\
\text { - Descriptive (Hyland, 2015) }\end{array}$ \\
\hline $\begin{array}{l}\text { Methodology - } \\
\text { distinguished } \\
\text { between four } \\
\text { possible research } \\
\text { approaches. }\end{array}$ & $\begin{array}{l}\text { Enables for mapping } \\
\text { the discourse in terms } \\
\text { of research methods. }\end{array}$ & $\begin{array}{l}\text { - } \quad \text { Qualitative (Burrows, 2017) } \\
\text { - } \quad \text { Quantitative (Jennings et al, 2017) } \\
\text { - } \text { Mixed (Ancona \& Mendelson, 2014) } \\
\text { - } \quad \text { Conceptual (Hyland, 2015) }\end{array}$ \\
\hline $\begin{array}{l}\text { Framing of } \\
\text { mindfulness - } \\
\text { captures the } \\
\text { framework based on } \\
\text { which mindfulness } \\
\text { practice is }\end{array}$ & $\begin{array}{l}\text { Detects } \\
\text { conceptualizations of } \\
\text { the practice. Papers } \\
\text { were coded only for } \\
\text { explicitly discussed } \\
\text { framings. For }\end{array}$ & $\begin{array}{l}\text { - Buddhism: framing mindfulness in Buddhist } \\
\text { concepts, sutras, interpretations (Orr, 2002). } \\
\text { - Psychological: framing mindfulness in Jon } \\
\text { Kabat-Zinn's work and/or involves empirical } \\
\text { studies associated with physical/mental } \\
\text { health and well-being (Jennings et al, 2017). }\end{array}$ \\
\hline
\end{tabular}




\begin{tabular}{|c|c|c|}
\hline $\begin{array}{l}\text { conceptualized } \\
\text { and/or studied } \\
\text { regardless of its } \\
\text { associations with } \\
\text { education. }\end{array}$ & $\begin{array}{l}\text { example, papers that } \\
\text { discussed mindfulness } \\
\text { in the context of } \\
\text { stress-reduction and } \\
\text { its psychological } \\
\text { effects and only } \\
\text { mentioned on passing } \\
\text { that mindfulness } \\
\text { originates in } \\
\text { Buddhism, were only } \\
\text { coded as } 2 \text {. }\end{array}$ & $\begin{array}{l}\text { Wisdom traditions: framing mindfulness in } \\
\text { diverse wisdom traditions (including } \\
\text { Buddhism) or in East-Asian wisdom } \\
\text { traditions other than Buddhism (Orr, 2002)) } \\
\text { epistemological: mindfulness framed as a } \\
\text { method of inquiry or "way of knowing" } \\
\text { sometimes referred to as contemplative } \\
\text { inquiry (Roth, 2006). } \\
\text { Ellen Langer's non-meditation-based } \\
\text { mindfulness: following exclusion criteria, } \\
\text { this category never appears as a single one. } \\
\text { (Borker, 2013) } \\
\text { Secular/spiritual/post-secular: framing that } \\
\text { discusses associations/dissociations } \\
\text { mindfulness in relation to an explicit } \\
\text { conception of secularity/spirituality (Hyland, } \\
\text { 2013). } \\
\text { Western philosophy (mostly existentialism } \\
\text { and phenomenology) (Todd, 2015). }\end{array}$ \\
\hline $\begin{array}{l}\text { Framing of } \\
\text { mindfulness in } \\
\text { education - } \\
\text { captures the } \\
\text { educational } \\
\text { rationale for } \\
\text { studying/ } \\
\text { implementing/discu } \\
\text { ssing/critiquing } \\
\text { mindfulness in } \\
\text { education. }\end{array}$ & $\begin{array}{l}\text { The development of } \\
\text { this current category } \\
\text { aimed to offer an } \\
\text { understanding of the } \\
\text { kind of educational } \\
\text { roles attributed to } \\
\text { mindfulness in } \\
\text { contemporary } \\
\text { literature. } \\
\text { Self-awareness was } \\
\text { coded } 3 \text { when framed } \\
\text { in a social context } \\
\text { and as a skill, and } 2 \\
\text { when it appeared as a } \\
\text { trait and/or as an } \\
\text { experience evoked } \\
\text { within the process of } \\
\text { teaching or learning } \\
\text { mindfulness. }\end{array}$ & $\begin{array}{l}\text { Well-being, physical and mental health } \\
\text { (Jennings et al, 2017) } \\
\text { - Self-knowing, transformative and lifelong } \\
\text { learning: mindfulness as cultivating aspects } \\
\text { of knowing ourselves including our } \\
\text { embodied and mental subjective experience, } \\
\text { identity, morality, sense of purpose, agency. } \\
\text { (Holland, 2004) } \\
\text { - Social-emotional learning: associate } \\
\text { mindfulness with a cluster of skills including } \\
\text { one or more of the following: self- } \\
\text { awareness, responsible decision making, } \\
\text { social awareness, relationship skills and self- } \\
\text { management (Durlak et al., 2011). } \\
\text { Academic performance, skills and cognitive } \\
\text { functions (Flook et al, 2010) } \\
\text { Processes of teaching and learning: } \\
\text { mindfulness as a way of enhancing teaching } \\
\text { and learning of subject matter across } \\
\text { disciplines. Papers fall within the growing } \\
\text { field of contemplative pedagogies (Repetti, } \\
\text { 2010) } \\
\text { Critical pedagogy and social inclusion: } \\
\text { viewed as a subtype of previous category, } \\
\text { particularly aimed at socially-engaged ethics } \\
\text { (Magee, 2016) } \\
\text { Behavior and conduct (Singh et al, 2013) } \\
\text { Education in the professions: mindfulness is } \\
\text { specifically framed as part of professional }\end{array}$ \\
\hline
\end{tabular}


education (e.g., social work, teachers)

(Magee, 2016)

- Spirituality: mindfulness here was applied toward aims such as human connection, empaths and self-knowing, which were specifically linked with "spirituality" (Wong, 2004).

Aim of paper -

Defines what the paper attempts to do in relation to mindfulness in education

Type of Effects of
implementation -
What effects are
attributed to the
implementation of
mindfulness (in
conjunction with
other practices
introduced within
the
implementation).
This unit of analysis
is called effects of
implementation and
not effects of
mindfulness per se,
given that many
implementations
involve diverse
practices, which are
not necessarily
referred to as
mindfulness.

Enables for an articulation of diverse perspectives from which mindfulness in education is discussed. These are captured by the verbs used in each coding (e.g. study, elucidate).

Empirical and/or conceptual papers in which effects were explicitly studied/measured were coded. Effects concerned with reduction of symptoms (e.g., anxiety, rumination) were coded 1 and not 2 . They may or may not be the consequence of improved emotional intelligence, yet we coded them more literally as indications of stress-reduction and wellbeing.
- Study effects and/or feasibility (Flook et al, 2010).

- Justify/Legitimize (Hyland, 2015)

- Critique of mindfulness (O’Donnell, 2015)

- Demonstrate/study how to implement (Holland, 2004)

- Elucidate (Roeser, 2014)

- Review/Assess the spread of (Zenner et al, 2014)

- Stress reduction and well-being: direct physiological indications of stress reduction and improvements in well-being (Jennings et al, 2017).

- Emotional intelligence: concern improvements in one's ability to become aware of, regulate and articulate one's inner experience and improve one's ability to handle difficult life situations. (Holland, 2004)

- Character and self-transformation: changes in how one perceives oneself and/or in one's engagement with life and/or profession. In distinction from category 2 this is a more abstract and less situation dependent effect (Wong, 2004).

- Socially-oriented effects: reflect a clear socially-engaged attitude (e.g., improved teacher-student relationships). (Jennings et al, 2017).

- Cognitive functions and academic performance (Flook et al, 2010).

- Teaching and learning processes, spirituality and lifelong learning: concerned with processes of learning rather than with measurable outcomes as in some of the other categories. (Holland, 2004).

- Student conduct (Singh et al, 2016).

- Adverse effects (Burrows, 2017). 


\begin{tabular}{ll}
\hline $\begin{array}{l}\text { General conclusions } \\
\text { of studies, which }\end{array}$ & $\begin{array}{l}\text { that which is believed } \\
\text { to be caused by }\end{array}$ \\
stem directly from & implementations, \\
findings within & implications depict the \\
empirical studies, & broader significance \\
and/or visionary & of the effect(s) to \\
statements that point & society/education. \\
to the future. &
\end{tabular}

Type of Implementation articulates the basic logistics of how mindfulness was incorporated into the educational setting.

\section{Placement in} Curriculum - the placement of the implementation in relation to the formal curriculum.
This was coded only when this unit of analysis was explicitly discussed, critiqued or studied.

Only papers in which such data was was found were coded.
(Jennings et al, 2017).

- Critical perspectives on mindfulness: entail any aspect of critique of the discourse/study of mindfulness in education (Greenberg \& Harris, 2012).

- Teaching and learning: implications that bear directly on the kinds of teaching and learning environments formed by implementations of mindfulness or conclusions as to effective implementations from the perspective of teaching and learning (Holland, 2004).

- Mindful and healthy society: associated with the broader effects of mindfulness in education for society (Wright et al, 2011).

- Reconceptualizing education/curriculum : moderate to radical understandings of the scope and possibilities of contemporary education (Napoli \& Bonifas, 2011).

- Mindfulness based intervention (Flook et al, 2010).

- Contemplative pedagogy: implemented for purposes, related to the learning of certain subject matter or professional skill (Holland, 2004).

- Mindful teaching/teacher: practiced/taught by the teacher (Hoyt, 2016).

- Cross-curricular mindfulness: broader mindfulness initiatives, or the interweaving of mindfulness practice throughout lessons and not as an intervention framed in weeks (Borker, 2013).

- One on one mindfulness: e.g., counselling sessions (Singh et al, 2016).

- Extra-curricular:introduced as an extra activity (Mrazek et al, 2013).

- During school hours (Wright et al, 2011).

- Across the curriculum (Roth, 2006).

- Higher education course (Wong, 2004).

- Teacher learning program (Jennings et al, 2017).

- The mindful teacher (Hoyt, 2016).

- Study group (Dufon \& Christian, 2013).

- Counselling sessions in school (Singh et al, 2016). 


\begin{tabular}{|c|c|c|}
\hline $\begin{array}{l}\text { Intensity of } \\
\text { implementation - } \\
\text { the relative density } \\
\text { of the } \\
\text { implementation of } \\
\text { mindfulness based } \\
\text { on frequency and } \\
\text { duration of sessions. }\end{array}$ & $\begin{array}{l}\text { Only papers in which } \\
\text { such data was was } \\
\text { found were coded. }\end{array}$ & $\begin{array}{l}\text { Low: Below } 7 \text { sessions of one and a half } \\
\text { hours (Levit \& Tarrasch, 2014). } \\
\text { Medium: } 7-12 \text { sessions of at least one and a } \\
\text { half hours. Some mindfulness-based } \\
\text { interventions and one-semester courses } \\
\text { followed this coding. (Wright et al, 2011). } \\
\text { - High: Above } 12 \text { sessions (Wong, 2004. }\end{array}$ \\
\hline $\begin{array}{l}\text { Population - The } \\
\text { age/profession of } \\
\text { the group(s) with } \\
\text { whom mindfulness } \\
\text { was implemented or } \\
\text { discussed. }\end{array}$ & & 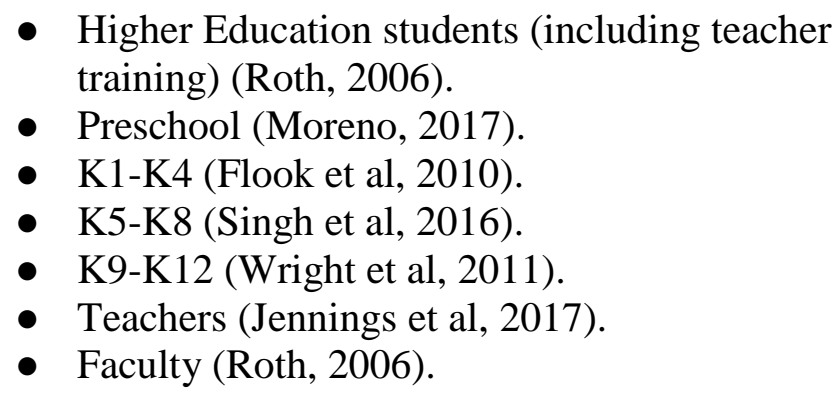 \\
\hline $\begin{array}{l}\text { Special } \\
\text { characteristics of } \\
\text { population - depict } \\
\text { the special } \\
\text { characteristics of the } \\
\text { population who } \\
\text { practiced } \\
\text { mindfulness when } \\
\text { these apply. }\end{array}$ & $\begin{array}{l}\text { Only papers that } \\
\text { discussed, critiqued or } \\
\text { studied actual } \\
\text { implementations were } \\
\text { coded. } \\
\text { Only papers in which } \\
\text { such data was was } \\
\text { found were coded. }\end{array}$ & $\begin{array}{l}\text { Learning difficulties and conduct problems } \\
\text { (Singh et al, 2016). } \\
\text { - Higher education students in specific } \\
\text { disciplines (excluding arts, physical } \\
\text { education \& health care) (Magee, 2016). } \\
\text { - Health care, service, and therapy professions } \\
\text { (Wong, 2004). } \\
\text { - Arts and body-oriented professions (e.g., } \\
\text { physical education) (Steyn et al., 2016). } \\
\text { - Ethnic diversity and Urban youth (Wright et } \\
\text { al, 2011). } \\
\text { - Economic status (Ancona \& Mendelson, } \\
\text { 2014). }\end{array}$ \\
\hline $\begin{array}{l}\text { Size of group - } \\
\text { depicts the size of } \\
\text { the group that } \\
\text { practiced } \\
\text { mindfulness. }\end{array}$ & $\begin{array}{l}\text { Only papers that } \\
\text { studied actual } \\
\text { implementations were } \\
\text { coded. }\end{array}$ & $\begin{array}{l}\text { - } \quad \text { Minimal less than } 10 \text { (Singh et al, 2016). } \\
\text { - } \quad \text { Small (10 - 49) (Ager et al, 2015). } \\
\text { - } \quad \text { Medium (50-100) (Kuyken et al, 2013). } \\
\text { - } \quad \text { Big (over 100) (Jennings et al, 2017). }\end{array}$ \\
\hline $\begin{array}{l}\text { Continent of } \\
\text { implementation - } \\
\text { depicts the continent } \\
\text { in which the } \\
\text { implementation } \\
\text { took place. }\end{array}$ & $\begin{array}{l}\text { Only papers that } \\
\text { discussed, critiqued or } \\
\text { studied actual } \\
\text { implementations were } \\
\text { coded, and when } \\
\text { details were provided. }\end{array}$ & $\begin{array}{l}\text { - } \quad \text { North America (Jennings et al, 2017). } \\
\text { - } \text { Asia (Tarrasch et al, 2017). } \\
\text { - } \quad \text { Europe (Kuyken et al, 2013). } \\
\text { - } \quad \text { Australasia (Ager et al, 2015). } \\
\text { - } \quad \text { South America (de Carvalho et al, 2017). } \\
\text { - } \quad \text { Africa (Steyn et al, 2016). }\end{array}$ \\
\hline
\end{tabular}

\section{Data Analysis Procedures}


After the qualitative coding, data analysis was based on descriptive statistics methods using SPSS. In exporting the initial excel file into SPSS, one line was assigned to each paper. At least one column was designated for each organizing theme. In order to represent the multiple coding possibilities for each organizing theme, the analysis was performed using multiple response descriptive statistics. The multiple response analysis enables us to present the data from several perspectives and to choose the most relevant and appropriate perspective by which to present each finding (e.g., presenting percent of papers or percent of cases depending on relevance).

\section{Results}

We present our findings beginning with a brief quantitative overview of the demographics of publications on mindfulness in education from 2002 to 2017 . We then focus on findings that concern the discourse of framings of mindfulness, its educational aims, implementation and implications.

\section{General Overview}

Figure 1 demonstrates a generally stable rise in publications beginning with two in 2002 and rising to 101 in 2017. More than half of the papers found $(238,53.2 \%)$ were published in the final three years of this period. 
Figure 1: Mindfulness in Education Publications by Year 2002-2017

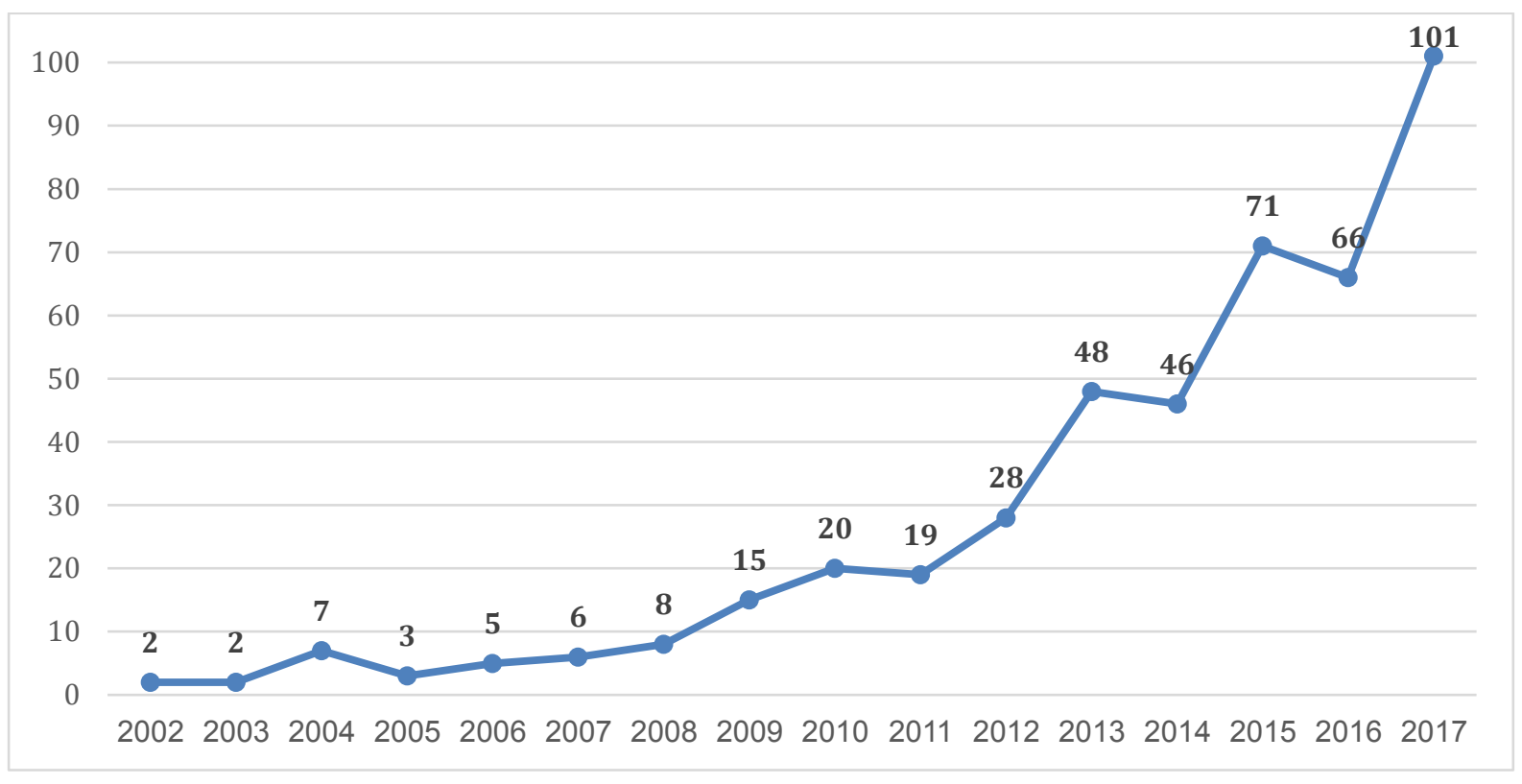

Figure 2 presents a breakdown of these publications according to their type (field research, review/meta-analyses or conceptual papers) for each year. There is a rise in the number of publications in all three domains with a drop in conceptual papers in 2017. Most apparent is the growth in field-based and oriented research (i.e., implementations, reflections on and self-studies of implementations), rising from 0 in 2002 to 64 publications in 2017. 
Mindfulness In and As Education

Figure 2: Breakdown of Publications According to Types

\begin{tabular}{|c|c|c|}
\hline & - Field research/ description & — conceptual \\
\hline $2017(N=99)$ & 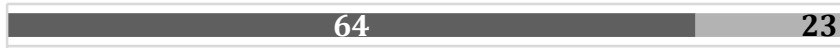 & 14 \\
\hline $2016(N=66)$ & $\begin{array}{rrrr}40 & 6 & 20 \\
\end{array}$ & \\
\hline $2015(N=71)$ & \begin{tabular}{|l|l|l|}
47 & 5 & 19 \\
\end{tabular} & \\
\hline $2014(N=46)$ & \begin{tabular}{|l|l|l|}
32 & 4 & 10 \\
\end{tabular} & \\
\hline $2013(N=48)$ & \begin{tabular}{l|l|l}
29 & 8 & 11 \\
\end{tabular} & \\
\hline $2012(N=28)$ & $\begin{array}{lll}9 & 8 & 11 \\
\end{array}$ & \\
\hline $2011(N=19)$ & $11 \quad 2 \quad 6$ & \\
\hline $2010(\mathrm{~N}=20)$ & $12 \quad 2 \quad 6$ & \\
\hline $2009(N=15)$ & $10 \quad 23$ & \\
\hline $2008(N=8)$ & 62 & \\
\hline $2007(N=6)$ & 42 & \\
\hline $2006(\mathrm{~N}=5)$ & B1 & \\
\hline $2005(\mathrm{~N}=3)$ & 3 & \\
\hline $2004(N=7)$ & 52 & \\
\hline $2003(N=3)$ & 211 & \\
\hline $2002(\mathrm{~N}=2)$ & 12 & \\
\hline
\end{tabular}

Figure 3 demonstrates the ratio between field based and oriented studies in comparison to conceptual papers demonstrating an overall trend favouring the former.

Figure 3: Ratio between Field-Based and Oriented Studies and Conceptual Papers

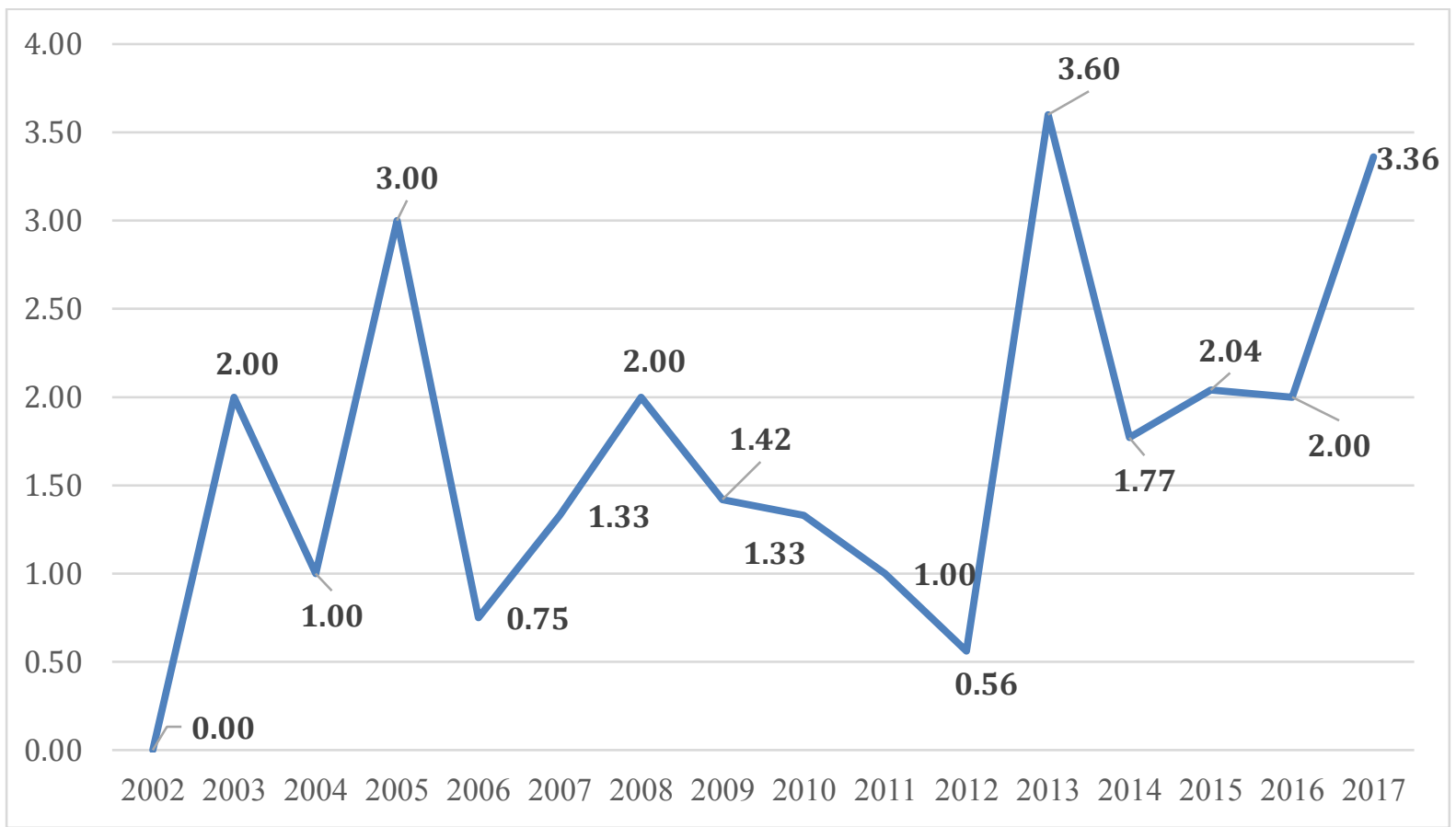


Table 2 presents the breakdown of 294 papers, which were identified as field-based and oriented studies by research method, age/population groups and worldwide spread. The table reveals a predominance of quantitative research, scarcity of PreK studies compared to other age groups, and an overall equal distribution between higher education implementations $(43.5 \%, N=128)$ and PreK-K12 implementations $(42.2 \%, N=124)$. Within this group of papers 256 involved actual implementation (e.g., excluding papers in which a lecturer reflects on his own mindfulness practice without his implementing it). These revealed a trend of growth in studies with over 100 participants over years (e.g., Jennings et al., 2017). Based on 236 publications that mentioned the location of implementation, a clear predominance of North America-located studies and near absence of South America and Africa-located studies were found.

Table 2: Research methods, population and worldwide spread in field-based and oriented studies on mindfulness in education 2002 to 2017

\begin{tabular}{|l|l|l|l|l|l|}
\hline $\begin{array}{l}\text { Methods of } \\
\text { inquiry }\end{array}$ & $\%(\mathbf{n})$ & Age group & $\%(\mathbf{n})$ & $\begin{array}{l}\text { Location of } \\
\text { implementation }\end{array}$ & \% (n) \\
\hline Quantitative & $\begin{array}{l}35.6 \% \\
(159)\end{array}$ & Pre K & $\begin{array}{l}2.4 \% \\
(7)\end{array}$ & North America & $\begin{array}{l}62.8 \% \\
(148)\end{array}$ \\
\hline Qualitative & $\begin{array}{l}14.5 \% \\
(65)\end{array}$ & K1-K4 & $\begin{array}{l}13.6 \% \\
(40)\end{array}$ & Europe & $14 \%(33)$ \\
\hline Mixed methods & $\begin{array}{l}8 \% \\
(36)\end{array}$ & K5-K8 & $\begin{array}{l}13.6 \% \\
(40)\end{array}$ & Asia & $13.4 \%(32)$ \\
\hline Conceptual & $\begin{array}{l}41.9 \% \\
(187)\end{array}$ & K9-K12 & $\begin{array}{l}12.6 \% \\
(37)\end{array}$ & Australasia & $8.4 \%(20)$ \\
\hline & Higher & $\begin{array}{l}43.5 \% \\
(128)\end{array}$ & South America & $0.9 \%(2)$ \\
\hline & & Teachers & $\begin{array}{l}13.3 \% \\
(39)\end{array}$ & Africa & $0.5(1)$ \\
\hline
\end{tabular}


Table 3 focuses on a group of $180(70.3 \%)$ of the 256 implementation studies in which mindfulness was implemented with specific populations. The table demonstrates a predominance of implementations within healthcare, service and therapy professions and a focus on ethnic diversity, urban youth and low socio-economic status.

Table 3: Specific populations in field-based and oriented studies of mindfulness in education 2002 to 2017

\begin{tabular}{|l|l|}
\hline Special characteristics of population & $\%(\mathrm{n})$ \\
\hline Health care, service and therapy professions & $51.1 \%(92,39$ of which focus on teachers) \\
\hline $\begin{array}{l}\text { Ethnic diversity, urban youth and low socio- } \\
\text { economic status }\end{array}$ & $19.5 \%(35)$ \\
\hline $\begin{array}{l}\text { Higher education in particular disciplines } \\
\text { (e.g., psychology, law, but excluding } \\
\text { arts/body-based) }\end{array}$ & $8.9 \%(16)$ \\
\hline Arts and body-oriented disciplines & $5.1 \%(9)$ \\
\hline Gifted education & $1.7 \%(3)$ \\
\hline $\begin{array}{l}\text { Learning difficulties (e.g. ADHD) or } \\
\text { conduct problems }\end{array}$ & $13.9 \%(25)$ \\
\hline
\end{tabular}

\section{Aims of papers in the discourse}

Based on the organizing theme of aim of paper, we found six different perspectives from which papers cover the field: study effects, justify, demonstrate how to implement/study, review/assess, elucidate, critique. Many papers received more than one coding. Overall, we found a discourse that is predominated by field-based and oriented publications focused on elucidating, demonstrating and studying the effects of mindfulness in education. However, papers that justify mindfulness in education comprise a substantial category $(\mathrm{n}=151,33.8 \%)$ of which 32 papers $(21 \%)$ were published until 2011 and 119 
papers (79\%) were published from 2011 to 2017. Critical papers were relatively few and began to appear in 2012. Their number remains mostly stable and comprises between to $2 \%$ to $4 \%$ of papers published each year, with no trend of growth detected. Some themes that were discussed in these papers include the critique of mindfulness as a commodified/diluted version of the practice (e.g., Hyland, 2017), lacking scientific rigor in research (e.g., Greenberg \& Harris, 2012) and adverse effects of the practice (e.g., Burrows, 2017).

\section{Framing of Mindfulness}

Though we coded 447 papers, we found 628 framings of mindfulness, because several papers framed mindfulness based on more than one framing. In $306(68.5 \%)$ papers we identified one framing, $105(23.5 \%)$ applied two framings, 28 (6.3\%) applied three and 8 $(1.8 \%)$ applied as many as four framings. Given this situation we chose to represent these framings based on percent and number of cases rather than based on percent and number of papers. The complexity at this level intensifies given that we did not find a clear pattern of combination of framings; they were rather combined diversely in different publications (figure 4).

Figure 4: Framing of mindfulness and their overlaps and relative presence in academic papers in the discourse of education 2002-2017.

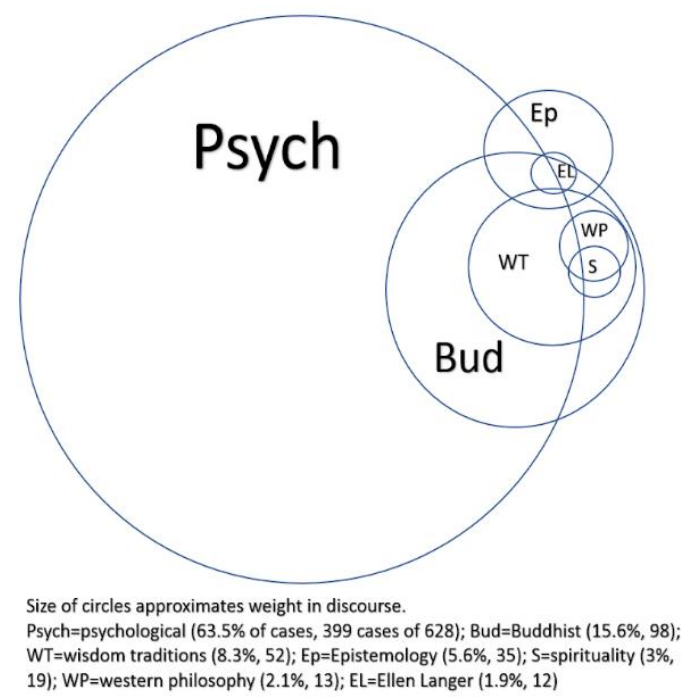


The two most frequent framings were psychological and Buddhist, with the former four times more frequent than the latter. Only 20 papers (4.5\%) did not frame mindfulness under either one of these two categories, and 71 (11\%) framed mindfulness based on both. The other five framings were marginal and almost never appeared as stand-alones. They included 52 papers that framed mindfulness based on wisdom traditions tying it to East-Asian traditions in general and not only to Buddhism (e.g., Taoism, Vedanta, yoga). Next, were papers that framed it based on epistemology, reflecting the practice as a way of knowing in some cases referred to as 'contemplative inquiry'. Only 19 papers specifically discussed mindfulness in the context of spirituality; even fewer papers tied it with western philosophy mostly grounding it in phenomenology and existentialism. Finally, 12 papers applied Ellen Langer's concept of mindfulness as an auxiliary framing (see our inclusion criteria).

We found a clear association between the framing of mindfulness and the paper's research method. Papers in which mindfulness was framed in relation to Buddhism, wisdom traditions, spirituality and/or western philosophy were mostly conceptual (76\%) compared to $24 \%$ empirical studies ( $7.7 \%$ quantitative, $11.3 \%$ qualitative, $5 \%$ mixed). In papers that framed the practice as psychological this pattern was reversed, with found $37 \%$ conceptual and $63 \%$ empirical (40\% quantitative, $14.6 \%$ qualitative, $8.4 \%$ mixed).

The psychological framing was often found to appear in conjunction with the term secular; however, the actual discussion of the meaning of "secularity" was rarely found; e.g., "secularized mindfulness practices" as those which "have been adapted for use in nonsectarian settings such as families, schools, clinics, and communities in ways that are attuned to individual needs and the requirements of culture, developmental stage, and historical age" (Roeser, 2013, p. 275). Though such occurrences were rare, "secularization" appeared more subtly in what seems to be an "apologetic" statement; e.g., "[M]indfulness originates from Buddhist philosophy, but the practice has been secularized and adapted to 
western society in programs such as mindfulness-based stress reduction for adults" (Tarrasch et al., 2017, p. 281, emphasis ours, see also Webster-Wright, 2013, p. 4). In most cases, after making such statement studies did not discuss Buddhism and some papers refrained from mentioning the origins of practice completely (e.g., Wright et al, 2011); however, this is not necessarily an indication that such mentioning did not occur when the intervention was delivered.

Further investigating the secularity versus religiosity/spirituality of this discourse in education, we created two clusters. A 'secular' cluster aggregated the framings psychological, epistemological, western philosophy and Ellen Langer's mindfulness, which are less likely to be considered in religious terms; an 'origins-based' cluster aggregated the framings of Buddhism, wisdom traditions and papers explicitly discussing spirituality, which are more likely to be considered religious-spiritual. Comparing these clusters in relation to field based and oriented studies, we found $456(75.5 \%)$ cases applying 'secular' framings and 148 (24.5\%) cases applying 'origin-based' framings. Among the conceptual papers 166 (61.9\%) cases applied 'secular' framings and 102 (38.1\%) applied 'origin-based' framings. In both field-based and oriented studies and conceptual paper there is hence a clear tendency to frame mindfulness in secular terms. In addition, examining 84 actual implementations applying the origin-based framings, we found 49 cases $(58.3 \%)$ in higher education and $18(21.4 \%)$ in PreK to k-12 students. Hence cases where origin-based framings are applied are clearly less common in primary and secondary settings.

Finally, we found that the ratio between papers in the secular cluster compared to the origin-based cluster grows between 2002 and 2017 (figure 5). Though this is not a fully linear progression there is an obvious secularization trend in this academic discourse. 
Figure 5: Ratio between Secular and Origin-bases Framings of Mindfulness 2002 to 2017

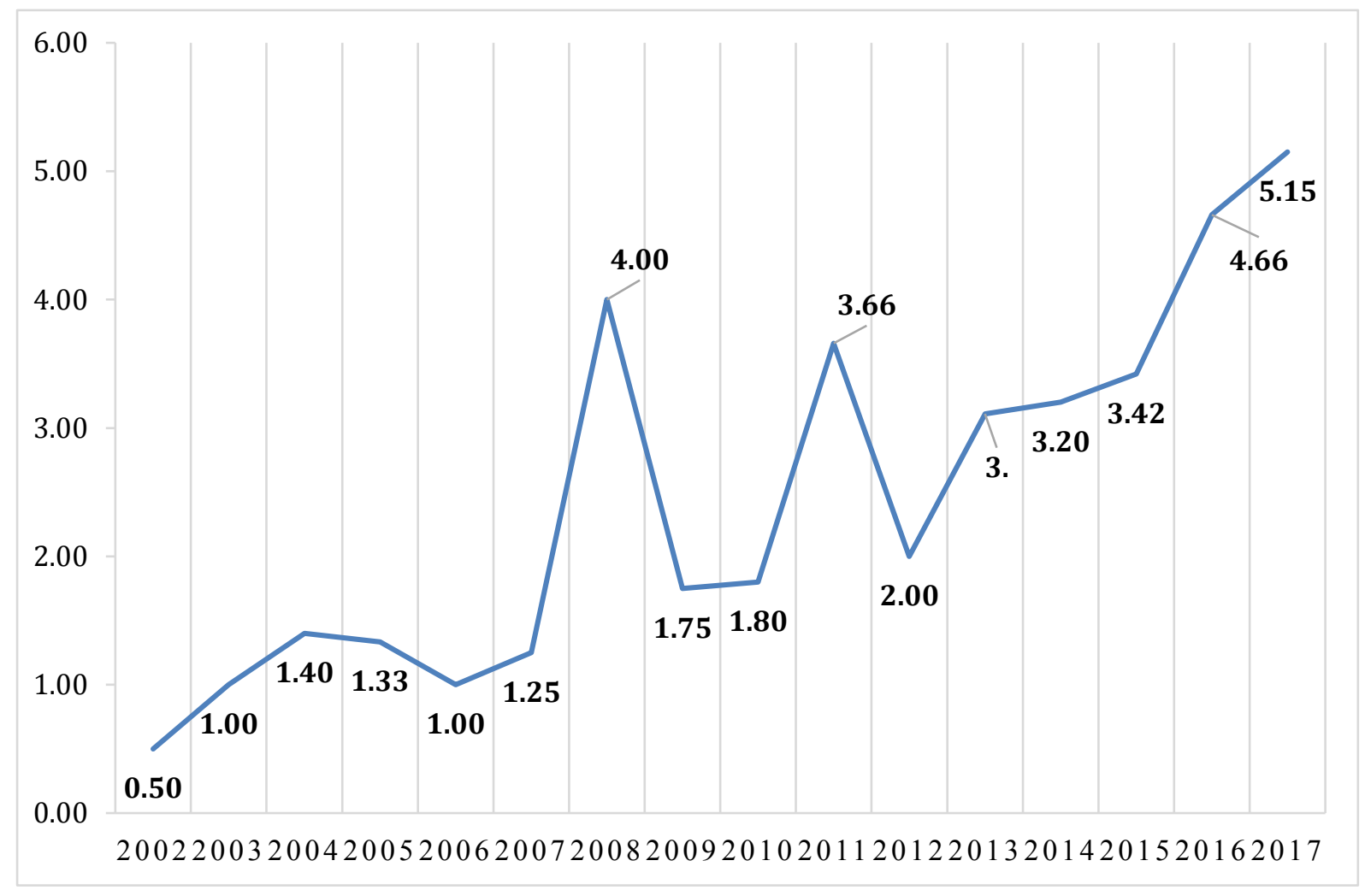

\section{Framing of Mindfulness in Education}

Findings concerned with the framing of mindfulness in education were treated in association with the related organizing theme of effects (see Table 1 of organizing themes). The former category reflects a top-down rationale that explains why and how mindfulness is associated with education. Such rationale had to be in the paper in order to be included in the research. However, the latter were effects of the actual implementation/study of mindfulness based on its framing in education. Effects were hence always particular expressions of the framing in education (e.g., framing mindfulness in terms of well-being, physical and mental health was associated with effects, such as stress-reduction and reduced rumination).

However, only 333 papers empirically studied or discussed them. Given the focus of this research on the discourse, findings on effects are mentioned only as an auxiliary organizing theme for the purpose of emphasizing certain aspects of the discourse. 
Framings of mindfulness in education were highly versatile beginning with 50 initial coding and reduced to nine categories (table 4).

Table 4: framings of mindfulness in education

\begin{tabular}{|l|l|l|l|}
\hline $\begin{array}{l}\text { Framing of mindfulness in } \\
\text { education }\end{array}$ & $\begin{array}{l}\mathbf{n} \\
\mathbf{( 8 4 4 )}\end{array}$ & \% of Papers & \% of Framings \\
\hline Well-being, physical and mental & 269 & $60.2 \%$ & $31.9 \%$ \\
\hline Socialth & 137 & $30.6 \%$ & $16.2 \%$ \\
\hline Self-knowing, transformative and & 125 & $28 \%$ & $14.8 \%$ \\
\hline lifelong learning & 111 & $24.8 \%$ & $13.2 \%$ \\
\hline education in the professions & 83 & $18.6 \%$ & $9.8 \%$ \\
\hline Academic performance, skills and \\
cognitive functions
\end{tabular}

Most papers were coded for more than one of each of these organizing themes.

Publications that fall within the predominating framing - Well-being, physical and mental health - commonly began with theoretical background, which depicted 
school/Universities/Colleges as stressful environments. They then elaborated on the ways in which stress can affect diverse aspects of students and teachers lives including studentteacher relationships, academic performance, student behavior and mental/physical health. In some papers this was discussed explicitly within a framework of education and well-being (e.g., Albrecht, 2014), while other studies focused on particular aspects within this domain, such as teacher burnout (e.g., Flook, Goldberg, Pinger, Bonus, \& Davidson, 2013), depression, anxiety, and sleep loss (e.g., Crain et al., 2017).

The second prominent framing of mindfulness in education was social-emotional learning (SEL). In these cases mindfulness practice was usually accompanied by additional practices that aimed to foster social-emotional competencies in students and teachers (e.g., Jennings et al., 2017). The third framing of self-knowing, transformative and lifelong learning stressed the role of mindfulness as a practice that involves introspection applied toward exploring ethics, subjectivity, identity, morality, sense of purpose, and agency (e.g., Holland, 2004). Fourth was the framing of academic performance, skills and cognitive functions, which applied specifically to executive functions, and often focused around attentional skills and their associations with academic performance (e.g., Mrazek et al, 2013).

Education in the professions commonly focussed on health care and service oriented professions, including teaching, practicing law, nursing, social work and consulting. This category was always accompanied with one of the previously-mentioned framings, hence attributing a specific role to mindfulness in these professions, such as social-emotional competencies in teaching (Jennings et al., 2017). However, the majority of these implementations focused on aspects of occupational health thus falling within the major category of well-being physical and mental health (e.g., Crain et al., 2017).

Unlike other framings, the framing of mindfulness in education in the context of processes of teaching and learning did not focus on the effects of implementing mindfulness; 
but rather on curricular-pedagogical processes engendered by mindfulness when incorporated in educational settings. This was tied with the discourse of contemplative pedagogy, that often framed mindfulness in epistemological terms, as a way of knowing, studying, and inquiring (e.g., Repetti, 2010). This framing was found to apply almost uniquely to higher education initiatives and often appeared in conjunction with one or more of three other framings: self-knowing, transformative and lifelong learning, education in the professions and critical pedagogy and social inclusion (shortly elaborated). However, the latter categories were found in papers that mostly focused on students' transformative processes, whereas processes of teaching and learning tended to focus on lecturers' perspectives featuring selfstudies/narratives of curricular design and implementation (e.g., Hoyt, 2016).

Three less common framings were: a) critical pedagogy and social inclusion - featured mindfulness as a practice which cultivates awareness to oppression, identity, gender, and race, sometimes grounded directly in Paulo Freire's work (e.g., Hyde \& LaPrad, 2015). b) behaviour and conduct - was specifically focused on mindfulness as a means for addressing violence, hostility and disruptive behaviour (e.g., Wright et al, 2011). It was found almost exclusively in primary and secondary educational settings. c) spirituality - concerned papers that clearly elaborated the meaning of this term and the way mindfulness and education are related to it. This usually had to do with conceptions of education in presence, wholeness and connectedness (e.g., Wong, 2013). This category was found almost exclusively in higher education initiatives.

We found that from 2008 at least $50 \%$ of the paper included the framing of wellbeing, physical and mental health and a trend of growth was found here with $70 \%$ of the papers in 2017 including this framing. SEL was hardly noticeable up until 2009, but from 2010 between $20 \%$ to $30 \%$ of papers include this framing, and in $2017,40 \%$ of them include it. Academic performance, skills and cognitive function and education in the professions 
reveal a similar pattern. Fifteen percent of the papers from 2010 include the former and $20 \%$ of the papers from 2010 include the latter.

\section{Aspects of Implementation}

We found five different types of implementations of mindfulness in the curriculum, with some publications that involved more than one type. MBIs predominate the discourse and are usually grounded in Jon Kabat-Zinn's development of mindfulness-based stressreduction courses (MBSR). However, almost all shifted from the standard MBSR curriculum (structured as 8 weekly sessions of approximately 2.5 hours each and an all-day silent retreat) (Kabat-Zinn, 2017), to programs that were adapted to accommodate to student age and/or to teachers' needs (Roeser, 2014). These adaptations applied to the duration of the intervention, frequency of sessions, and lengths of practices implemented. Of 144 interventions that provided data on intensity of implementation, 74 (51.4\%) were low intensity interventions (less than 7 sessions of $1 \mathrm{~h} 30$ min or if not structured in weekly sessions, less than $10 \mathrm{~h} 30$ min overall). Fifty nine ( $41 \%$ of interventions) were of medium intensity ( $7-12$ sessions of at least $1 \mathrm{~h} 30 \mathrm{~min}$, or between $10 \mathrm{~h} 31 \mathrm{~min}$ to $18 \mathrm{~h}$, which is close to the intensity of a standard MBSR course), and 11 (7.6\% of interventions) were of high intensity (over 12 sessions of 1h30min, or over 18h). We did not find a consistent spread of the intensity of interventions related to ages (such as, a potential preference for low intensity in younger ages). Overall we found a trend of growing intensity over years (taking all types of implementations together) with $63.4 \%$ cases of higher intensity published from 2015 to 2017.

Seventy implementations (20.3\%) were coded as contemplative pedagogy of which 52 were actual implementations and 20 involved conceptualizations of this domain. These reflected applications of mindfulness as a pedagogical practice applied toward the teaching of a variety of 20 different disciplines, such as psychology (Levit-Binnun \& Tarrasch, 2014), law (Magee, 2016), communication (Huston et al., 2011), and business (Borker, 2013). This 
category was found almost exclusively in higher education $(N=63,90 \%$ of the contemplative pedagogy implementations). Within it, 38 papers provided details on implementation logistics, reflecting a tendency toward high intensity implementations (11 low, 13 medium and 14 high).

The category of cross-curricular mindfulness found in 39 of the implementations (11\%), referred to incorporations of mindfulness that permeate the curriculum of individual courses or appear across programs with differing degrees of intensity (23 papers that provided details were found - 7 low intensity, 11 medium, 5 high). Two additional small categories were found: Mindful teacher (14 papers, $4.1 \%)$ and one-on-one mindfulness (7 papers, $2 \%$ ). The former mostly applied to self-studies in which teachers who have a personal mindfulness practice reflected on the ways in which the practice affected their teaching with or without relation to their actually implementation of the practice with their students. The latter category reflected mindfulness integrated into counselling sessions either as part of counselling sessions or as part of an intervention.

We found three main categories of placement of mindfulness in the curriculum: 80 (33.6\%) cases of higher education courses that integrated mindfulness as an intervention or as contemplative pedagogy, 74 (31.1\%) intra-curricular interventions (i.e., during school hours) and $55(23.1 \%)$ extra-curricular interventions. We found a growing tendency to treat mindfulness as an intra rather than an extra-curricular practice. The trend begins in 2013, with $17(53.3 \%)$ intra-curricular placements and 12 (37.5\%) extra-curricular, compared to 2016 with 26 (75.3\%) intra-curricular placements and 7 (20\%) extra-curricular, and continues in 2017 with 37 (86.1\%) intra-curricular placements and 4 (9.3\%) extra-curricular implementations.

We found associations between framings of mindfulness, type of implementation and the kinds of effects sought/reported. Generally, papers framing mindfulness under psychology 
and those studying MBIs tended toward a set of clearly defined and measurable effects (e.g., decreased negative accent, improved sleep), whereas the framing of Buddhism/wisdomtraditions/spirituality and contemplative pedagogy implementations were inclined toward abstracter and process-oriented effects (e.g., finding meaning, self-knowledge). Hence over $70 \%$ of papers using the psychological framing, and close to $80 \%$ of MBIs were associated with the effects category of "well being and stress reduction", compared to $36 \%$ of papers using the Buddhist framing and $15 \%$ of contemplative pedagogy implementations associated with these. Conversely $15 \%$ of paper using the psychological framing and $35 \%$ of MBIs were associated with the abstracter effects categories of "character and self transformation" and "transformative and learning/teaching processes", compared to $70 \%$ of those using the Buddhist framing and 50\% of contemplative pedagogy implementations associated with them.

\section{Analysis of paper implications}

All papers received at least one coding for the organizing theme of implications, which referred to final statements/conclusions that researchers suggested based on their findings/claims. We found five kinds of implications, which were also linked to the framing of mindfulness, its framing in education and the type of implementation. Most common were implications concerned with feasibility/effectivity and cost-effectiveness of mindfulness in education (278 papers, $62.2 \%$ ). This was a characteristic of empirical (usually quantitative) studies, that naturally follows the structure of papers of MBI research that was mentioned above. Implications concerned with reconceptualizing education/curriculum (178 papers, $40 \%$ ) involved moderate to radical critique of current curricular-pedagogical practice. They were found to be the main implications in papers that framed mindfulness under Buddhist, spiritual, epistemological or based on wisdom traditions, but not in papers that frame it as 
psychological. Mindfulness was construed here as a means for introducing education that is more humane and sensitive. Implications associated with critical perspectives on mindfulness (81 papers, $18.3 \%$ ) included considerations of implementation and effects of the practice as well as critique of the ethics of mindfulness in the curriculum and its future. Implications in the domain of teaching and learning (64 papers, 14.4\%) discussed framings and effects concerned with the implementation of mindfulness for pedagogical purposes. These were more pronounced in papers that framed mindfulness under Buddhism and generally carried a positive tone as to the kind of learning climate and experiences that are engendered by the application of mindfulness in teaching/learning. A small group (18 papers, 4\%) discussed a mindful and healthy society, offering statements that were associated with the broader effects of mindfulness in education for society.

\section{Discussion}

Indications of the growth of publications on mindfulness in education combined with a variety of approaches toward and critique of its implementations and aims, have led us to engage in a grounded mapping of this field. Based on the coding of 447 peer-reviewed papers published between 2002 and 2017 we indeed found an exponentially growing and highly complex field. We divide our discussion into four sections: general overview, framings of mindfulness as a source of the discourse's complexity, mindfulness in and as education as a map of this discourse, and summary and future directions.

\section{Mindfulness moving toward the mainstream}

The exponential growth of the academic discourse of mindfulness in education is evident from our findings. A similar trend has been described by Schonert-Reichl and Roeser (2016); however they found 155 papers between 2000 and 2014 (p. 4), whereas we found 209 papers from 2002 to 2014 . This discrepancy is probably due to our broader selection criteria 
(e.g., our inclusion of studies on ADHD in educational settings). Setting this discrepancy aside our findings strengthens their detection of a general pattern of steady rise in publications in the field.

The period of 2015-2017, which was not covered by Schonert-Reichl and Roeser, has been highly significant both quantitatively and qualitatively. During these three years the amount of publications has more than doubled, and this has brought some shifts in the distribution of papers within the discourse. Compared to Schonert-Reichl \& Roeser (2016), who found approximately half of the papers conceptual and half empirical, we found a clear shift toward field-based and oriented studies rather than conceptual papers. Our findings also showed that over years there are more studies of larger groups.

A further shift from Schonert-Reichl and Roeser's (2016) study was found in the domain of mindfulness for teachers/educators. They found only $6 \%$ of the studies addressing this domain and hence pointed to "the need for more attention to the adults in school settings who "create the weather" for students" (p. 5). This call seems to have been heeded given that the publications from 2015 to 2017 reflect more than a twofold relative increase in this particular domain (see Lomas et al, 2017). Two domains, however, seem to remain stable across both reviews. One, is an even distribution of studies between postsecondary publications and preK-K12 publications; the other, mindfulness in preK ages, which continued to be a relatively neglected area of study.

Additional indications of the growth of the field are reflected in the substantial rise in reviews and meta-analyses. The appearance of review studies naturally lags behind fieldimplementation studies with the first two published only in 2009 , followed by relatively small numbers of reviews in subsequent years yet these numbers become far more significant in 2016 and 2017. Furthermore, the reviews in and of themselves progress from general reviews in the early years (e.g. Burke, 2009; Meiklejohn et al., 2012), to growing specificity in age 
and population in recent years; e.g., young children (Moreno, 2017), K1 to K12 (Zenner et al., 2014), teachers (Lomas et al., 2017), and college students (Bamber \& Schneider, 2016). Growing specification in reviews not only suggests the presence of enough age/populationspecific studies as data for review; it also reflects the trajectory of development in an academic field, which is likely to emerge as a general field and overtime branch into subdiscourses (e.g., mindfulness in adults, mindfulness for teachers).

The findings of aims of papers point both to the nascency of this discourse but also to its development. The richness of six categories of aims of papers depicts a diversity of perspectives, however, over a third of the papers involved justifications for the discourse. Only a nascent field would require such substantial debate around its very existence. At the same time, it is likely that given this initial phase in the discourse and the uncanniness of the practice, the more it is implemented, the more challenges, critique and difficulties arise. This in turn calls for the need for justifications. Our prediction is that over the next decade, if the discourse continues to grow in the same pace, the relative share of this type of papers will diminish.

The nascency of the field is expressed in a surprising and potentially unhealthy paucity of critical papers in this field. The amount of critical papers found seems small and possibly suggests an immature and over-optimistic phase of this discourse. Such trend has already been detected by Greenberg and Harris (2012) who argued that enthusiasm for promoting mindfulness "outweighs the current evidence supporting them" (p. 161). A similar claim has been made more recently within the general discourse of mindfulness, suggesting that this is still the case and not only in implementation in education (Van dam et al., 2018). There is a certain paradox in proposing that lack of critique reflects a weakness in a field. However, following Karl Popper's conception of science we suggest that the strength of a 
field is revealed when it withstands attacks and attempts to refute its claims, rather than in the absence of these.

Summing this part of the discussion, however, in the course of sixteen years the discourse of mindfulness in education has been clearly moving from the margins in the direction of the mainstream. Yet, that which is moving into the mainstream is a highly complex domain as we now discuss.

\section{What is that thing called "mindfulness" and how secular is it?}

Our findings suggest that framings of mindfulness practice and framings of mindfulness in education are two discrete organizing themes that need to be handled separately. Moreover, we argue that the framing of mindfulness is a primary and crucial source for explaining the perplexing variety of possibilities in this discourse (figure 4). This is manifested in four main findings in this particular area: a) there are seven different distinct framings of the practice associated with very different domains of life and socio-cultural contexts (e.g., mental-health, Buddhist-ethics, epistemology); b) a substantial amount of papers apply more than one framing; c) some papers apply as many as four different framings; d) framings are combined in various patterns. Understanding the diversity of mindfulness in education begins with the conception(s) of the practice itself even prior to considering its associations with education.

As we suggested in the introduction, the most apparent complexity here involves the origins of the practice within Buddhism (and sometimes other wisdom traditions), which ground it in an existential and/or ethical worldview and construes it as part of a broader way of being (Gethin, 2011; Olendzki, 2011), versus its far more recent psychological-scientific research-based perspective that stresses its salutary effects on physical and mental health (Bishop et al, 2004; Kabat-Zinn, 1994). These were indeed found to be the two main framings of the practice. The amount of publications that did not apply either one of these framings was negligible. 
The two framings mostly appeared separately and were also handled in research in different ways, with the former mostly studied conceptually, and the latter mostly studied empirically with a tendency toward quantitative methods. This trend of separation suggests that the discourse tends to maintain a dichotomy of mindfulness as related to its origins versus its association with psychology. This bifurcated pattern is manifested in implementations as later discussed. The group of papers that applied the two framings jointly could have potentially suggested a third strand, which transgresses this split, yet these were almost always conceptual papers. This proposes that at this point the discourse shuns from studying the two framings jointly within empirical studies. That is, when mindfulness is framed as origin-based it is rarely studied empirically in education. This finding is not surprising, given that the issue of measurement in mindfulness studies is a thorny one. Some have argued that the contemporary questionnaires that supposedly quantify mindfulness hardly reflects the Buddhist concept (Nelson, 2012; Rosch, 2006). Our findings of qualitative differences between the more concrete effects of implementation when mindfulness is framed as psychological versus their abstractness when framed as origin-based manifests such difficulties.

We found that not only is the majority of implementations of mindfulness in education "secular" (see also Hyland, 2015), there is also a trend of secularization. Over years it seems that Buddhist terminology associated with the practice is more frequently attenuated or intentionally omitted. This secularization is also supported by the utter marginality of the term - spirituality - as a framing of mindfulness, despite potential expectations that stem from colloquial perspectives, which associate mindfulness with this term. The discourse is clearly aiming toward a consensual social space in as far as proselytizing a religion to students is concerned and most notably so in primary and secondary education (see also Jennings, 2016). However, it should be bore in mind that secularization may be mitigated by the general 
growth of this entire discourse. Such growth inevitably implies more exposure to Buddhist mindfulness even if its relative proportion is diminishing.

The Buddhist/psychology or more broadly the origin-based/secular dichotomy within the framing of mindfulness reflect a coarse resolution of this discourse as internally split. Within this split, however, a richer diversity that is manifested in the four findings mentioned above still holds. Within education writ large mindfulness is associated with western philosophy (e.g., Todd, 2015), epistemology and ways of knowing (e.g., Hart, 2004), wisdom traditions that are not necessarily Buddhism (e.g., O'Donnell, 2015) and conceptions of spirituality (e.g., Wong, 2004). These framings and their diverse combinations attest to the variety of possibilities that this 'thing' or 'these things' called mindfulness practice are. This complexity further intensifies as the various framings of mindfulness meet educational settings.

\section{Mindfulness in and as education: Why and How is Mindfulness Implemented?}

The discourse of mindfulness in education is comprised of layers of complexity, that were excavated based on the organizing themes of this research. The seven diverse framings of mindfulness practice further diversify within nine framings of mindfulness in education, five types of implementation of varying intensities and modalities associated with a variety of effects and implications (figure 6).

Figure 6: Layers of complexity in the academic discourse of mindfulness in education

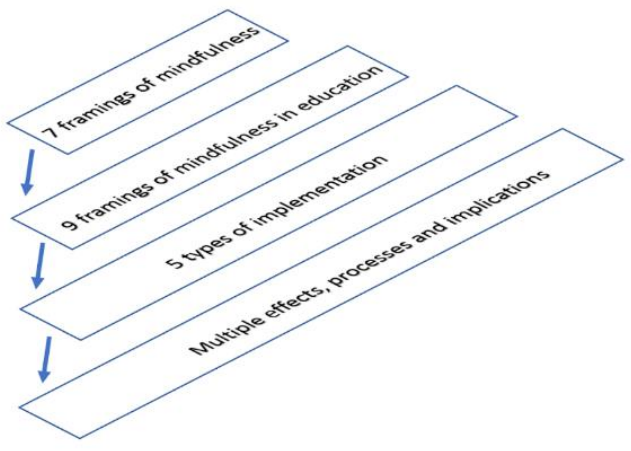


Mindfulness In and As Education

Taking into consideration the variety of combinations that emerged based on these layers of complexity as represented in our findings, we developed a map that models the field (figure 7). 
Figure 7: Map of the academic discourse of mindfulness in/as education 2002 to 2017

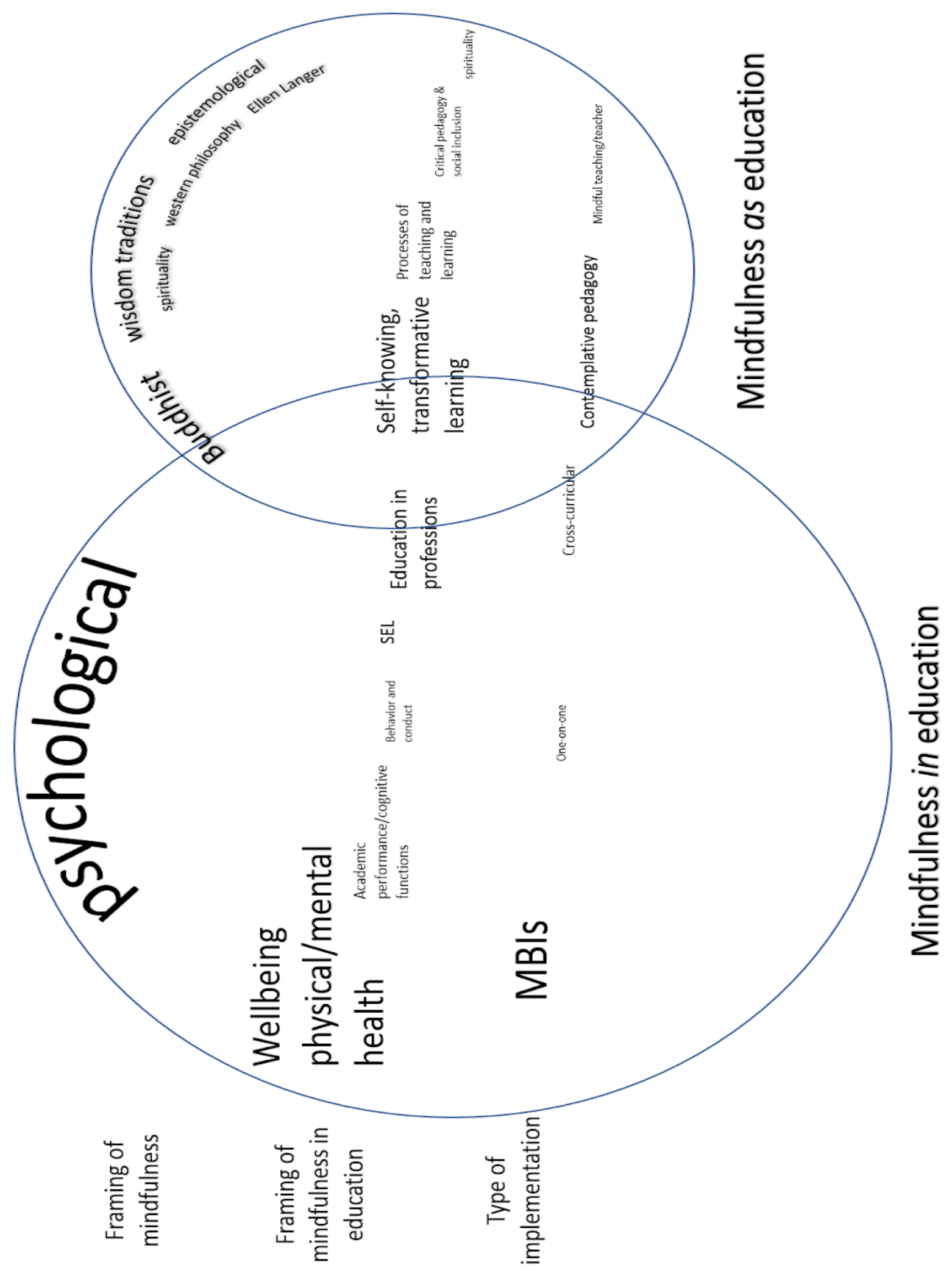


Two higher order patterns emerged as characterizing the discourse of mindfulness in education during the studied period: mindfulness in education and mindfulness as education. The size of the fonts applied approximates the dominance/negligibility of categories indicated. In the following we elaborate mindfulness in and as education with the aid of figure 7 and table 5, which presents these two patterns in a skeletal form.

Table 5: The two main patterns of mindfulness in education 2002-2017

\begin{tabular}{|l|l|l|}
\hline Characteristic & Mindfulness in education & Mindfulness as education \\
\hline Framing of practice & Psychological & $\begin{array}{l}\text { Process-oriented integrated in } \\
\text { education }\end{array}$ \\
\hline $\begin{array}{l}\text { Framing of role in } \\
\text { education }\end{array}$ & $\begin{array}{l}\text { Well-being, physical and } \\
\text { mental health. SEL, academic } \\
\text { performance, skill and } \\
\text { cognitive functions, education } \\
\text { in the professions. }\end{array}$ & $\begin{array}{l}\text { Buddhist, wisdom-traditions, } \\
\text { epistemological }\end{array}$ \\
$\begin{array}{l}\text { learning, Self-knowledge, } \\
\text { learning, education in the } \\
\text { professions, critical pedagogy and } \\
\text { social inclusion, spirituality in } \\
\text { education. }\end{array}$ \\
\hline $\begin{array}{l}\text { Modality of } \\
\text { implementation }\end{array}$ & MBIs & $\begin{array}{l}\text { Contemplative pedagogy and } \\
\text { cross-curricular approaches }\end{array}$ \\
\hline Ages & Across ages & $\begin{array}{l}\text { Higher education with very few } \\
\text { examples of primary schools }\end{array}$ \\
\hline Research method & Empirical (mostly quantitative) & $\begin{array}{l}\text { Diverse, mostly self-studied and } \\
\text { conceptual but rarely quantitative }\end{array}$ \\
\hline Examples & $\begin{array}{l}\text { Bakosh et al., 2016; Flook et } \\
\text { al. 2010; Napoli et al. 2005. }\end{array}$ & $\begin{array}{l}\text { Berila, 2015; Magee, 2016; } \\
\text { Tarrasch, 2017 }\end{array}$ \\
\hline
\end{tabular}

\section{Mindfulness in education.}

The term 'mindfulness in education' reflects a systemic understanding of the practice (Left circle figure 7, left column table 5). It enters contemporary education in order to support/scaffold the educational system's functioning, to enhance students' and teachers functioning, performativity and well-being within it, and growingly also to support a 
nurturing climate in educational settings. The main vehicle of mindfulness in education is outsourced MBIs that are offered across all ages and educational settings, framed mostly in psychological terms and aimed primarily toward well-being, physical and mental health, growingly toward SEL, and toward academic performance, skill and cognitive functions. Interventions, as the primary type of implementation of mindfulness in education, implies that the practice is "extra-territorial"; that is, unlike, conventional curricular activities, it is offered for a fixed, usually short span of time, and is often outsourced. Our findings that overtime MBIs are becoming an intra rather than an extra-curricular activity and the growth in higher intensities of implementation may be significant here. Such trend may potentially reflect a shifting understanding of education and schooling as including such activities.

The target of many mindfulness in education studies was to address adverse effects of stress on well-being and social, emotional and academic lives of students and teachers based on mindfulness' studied salutary effects in this domain (e.g., Flook et al, 2013). This was observed across primary, secondary and postsecondary settings in general but there is an emphasis in research on education in service and healthcare professions (e.g., Beddoe \& Murphy, 2004), and on populations of ethnic diversity, urban youth and low socio-economic status (e.g, Wright et al., 2014). The association of MBIs with SEL is becoming more noticeable in general, and particularly in the domain of mindfulness for teachers (Jennings et al., 2017). This orientation reflects the extension of the therapeutic orientation of MBIs toward socially-oriented educational aims that with time may push mindfulness further toward finding a more natural place within education (Hyland, 2009; 2015). A smaller category of mindfulness in education was found in MBIs aimed at the enhancement of academic performance, skills and cognitive functions (e.g., Bakosh et al., 2016; Mrazek et al, 2013), sometimes specifically aimed at learning difficulties and conduct problems (e.g., Singh et al, 2016). Though the link between social-emotional learning and academic 
achievements is addressed in the general literature of SEL (Durlak et al., 2015), the link of the latter two with mindfulness at this point reflects a small portion of the overall discourse of mindfulness in education. Scarcity of research directly focused on academic achievements, may be explained by the difficulty involved in establishing their direct relation to interventions within schools environments.

Looking more critically at the MBI phenomenon, papers uncovered during the research raised challenging questions regarding the educational implications of this type of implementation. These critiques involved the ethical basis of MBIs, their overall aim and their actual impact. Hyland (2017) discussed the commodification of the practice, referred to as "McMindfulness". He argued that mindfulness requires its origin-based ethics in order to become more than a passing fad. To some degree MBIs stressing SEL respond to this critique; especially when grounded in models, such as the prosocial classroom that links teacher well-being and social-emotional competencies with classroom climate, studentteacher relationships and positive developmental outcomes in students (Jennings \& Greenberg, 2009; Meiklejohn et al., 2012). This orientation reflects some mindfulness in education publications that make a point of emphasizing the socio-ethical nature of mindfulness (Davidson et al., 2012), possibly even when implemented as an MBI and not necessarily grounded directly in Buddhist ethics. The recurrent "apologetic" statement found across MBI publications (i.e., "mindfulness originates in Buddhism but it has been secularized..."), however, demonstrates the struggle of mindfulness in education for legitimacy in the face of the Buddhist origins of the practice. A debate on whether and how mindfulness can remain secular and still promote a robust ethical worldview seems to be a subtext that accompanies this discourse (see Hyland, 2017; Jennings, 2016; Purser \& Melilo, 2015). Other critics challenged the therapeutic-medical agenda of MBIs. The flipside of MBIs' ameliorating teacher burnout is that they may at the same time acclimatize teachers to 
a sick system that is responsible for the conditions that create burnout in the first place (Reveley, 2015). From this perspective radical critics construe MBIs as Neoliberal practices in disguise (Forbes, 2019).

Another challenge to mindfulness in education concerns the sustainability of this pattern. The majority of MBI studies we found were based on outsourced teaching and with low to medium intensities (see also Zenner et al., 2014). When considering this in light of the broader context of schooling, six to eight weeks of one-hour sessions compared with days, weeks, months, years of regular schooling activities seem like a drop in the sea. Some have hence began to suggest more robust conceptions of mindfulness in education in teacher education stressing the potential of the practice to support teaching and school climate (e.g., Lomat et al., 2017; Roeser et al, 2012).

Critics of mindfulness in education are generally not opposed to the implementation of mindfulness practice in education as such. Rather, they reject certain kinds of applications and justifications for the practice, and often propose ways by which to transgress these difficulties (O’Donnell, 2015). This often points to the second pattern we now describe within mindfulness as education.

\section{Mindfulness as education.}

Mindfulness as education shifts from a positioning of the practice as a means for supporting/scaffolding education to its positioning as part and parcel of the educational process. Here, mindfulness was not an outsourced intervention that comes from outside the educational domain and framed mostly in therapeutic/medical/psychological terms. It was rather implemented by lecturers/teachers/school-staff framed mostly within Buddhism, wisdom traditions and epistemology, and its framing in education revolved mainly around teaching and learning processes, self-knowledge transformative and life-long learning, critical pedagogy and social inclusion and education in the professions. This intention was 
manifested in research methods. If mindfulness in education was mostly studied empirically and quantitatively tended to construe it as an instrumental effects-driven pattern, mindfulness as education, leaning toward conceptualization and self-studies reflected a less or noninstrumental process-driven pattern. The medium of research tends to frame mindfulness in education as less concerned with the processes of implementation and education and more concerned with their result; whereas mindfulness as education tends to focus on issues of implementation and integration with educational processes. Implications of studies naturally followed this pattern with mindfulness in education research often focused on feasibility, effectivity and/or cost-effectiveness and mindfulness as education more focused on reconceptualizing education/curriculum.

Under mindfulness as education we found a number of modalities. Contemplative pedagogy, implied the incorporation of mindfulness toward teaching subject matter in engaging, experiential and inquiry-based ways. This appeared in cases, such as Levit-Binnun and Tarrasch (2014) in which a lecturer applied mindfulness as an experiential pedagogy that enabled students of psychology to engage in the learning of brain theory introspective practice. Here the practice was framed under epistemology, and research methods given its conception as a way of knowing and inquiring referred to as 'contemplative inquiry' (Komjathy, 2018).

Cross-curricular types of implementation, were rare examples in which mindfulness was interwoven into school or university culture in more robust ways. This was found for example in primary education where a 'mindful language' was integrated throughout the curriculum (Tarrasch, 2017) but also in higher education programs that concentrated on contemplative practices in general (Roth, 2006).

Education in the professions constituted a group of papers that demonstrated/conceptualized or studied ways in which mindfulness was integrated toward 
professional ethical decision making, social justice, compassion, and attentive communication. This was most pronounced in professions, such as social work, business, education, communication, and law (Borker, 2013; Huston et al., 2011; Wong, 2004). These cases were less common than those of MBIs within the professions, which were grounded in therapeutic aims of occupational health characteristic of mindfulness in education (e.g. Crain et al, 2016).

Critical pedagogy and social inclusion comprised of implementations of mindfulness with a social-critical and sometimes radical orientation. Some of these reflected incorporations of mindfulness toward cultivating social-engagement and an ethics of diversity and inclusion (Berila, 2015). In other cases this appeared within education in the professions, for example in law education that incorporated mindfulness toward raising awareness to social biases (Magee, 2016). These cases are potential responses to critique of mindfulness practice as self-indulgent (see Hyland, 2009) or to those mentioned, concerning the potential Neoliberal agenda of MBIs (Forbes, 2019; Reveley, 2015).

A critical perspective on mindfulness as education that we would propose is that despite what seems to be a creative and transformative domain, it is not surprising that it is uncommon. The examples of contemplative pedagogy we came across as well as the crosscurricular 'whole-school' approaches were heavily dependant on lecturers and teachers that were themselves grounded in mindfulness practice and/or highly committed and activist educators. It is a pattern that is characterized by a grassroots movement that depends on the drive and charisma of these individuals. This inevitably makes mindfulness as education a more unique phenomenon that is unlikely to "scale up". That said, it is questionable whether at all scaling up is to be pursued in such case for it is not clear whether there are or can be 'protocols' to follow in this case. Mindfulness in education's potential to further develop 
seems more plausible given its more conformist agenda. This conformism has its prices as critics above suggested; however, scholars are working to address at least some of them.

\section{Summary and future directions}

Summing our discussion, mindfulness enters the curriculum through two quite different and distinct patterns: mindfulness in education that is more extra-educational and effects-oriented; mindfulness as education that is integrated with curricular-pedagogical practice and is process-oriented. Mindfulness in education appears across ages, pulls toward a secularized, psychological orientation that tends toward interventions with concrete measurable effects mostly revolving around well-being physical and mental health. Mindfulness as education carries a more profound transformative educational potential relying more on the practice's origins and integrated through contemplative pedagogy and some more holistic models with process-oriented aims.

From a broader perspective, these two patterns embody the pull of two historicaleducational orientations that can be found in Plato's Republic as well as in contemporary scholarship - education toward wisdom and virtue on the one hand, and education as a process of socialization, skill-acquisition, and economic-needs. At this point, the former seems to be more marginal even if noticeable in some robust higher education attempts to incorporate and critically examine mindfulness (and other contemplative) practices. The latter is more pervasive and is present in attempts to apply mindfulness as a way to address day-today systemic problems such as teacher stress and burnout.

In spite of the exponential growth in publications we still find a number of weaknesses in the discourse. It is important to point these out both for the purpose of understanding the existing discourse and for opening a variety of future possibilities for theory and research. 
First, this may be one discourse when viewed from the perspective of mindfulness practice as a unifying phenomenon (figure 6), yet as figure 7 and table 5 demonstrate, it is a split discourse marked by psychological-secular versus origin-based framings. This split very much determines two patterns of framing in education, implementation, research and implication. It reflects an inner tension within this discourse in which secularizing and familiarizing mindfulness through MBIs may reduce the more robust ethics that it can potentially bring with it from its origins. However, without this process mindfulness may have well remained outside the educational discourse as has been the case prior to this progression. It is questionable whether there is a way to strengthen the ethical basis and sustainability of MBIs without falling into traps of their being viewed as proselytizing. It remains to be seen whether MBIs are a step toward a more sophisticated integration of mindfulness into education.

We suggest that diversifying research may be a way to shed light on mindfulness in and as education and advance toward a richer discourse. There are exceptions to the general dichotomy discussed with qualitative and mixed studies of MBIs (e.g., Ancona \& Mendelson, 2014) and quantitative studies of implementations of contemplative pedagogy (Huston et al., 2011); however, these are relatively rare. This is a paradoxical feature of this discourse because the plurality of framings of mindfulness and framings of mindfulness in education stands in opposition to the dualistic pattern in research methodologies and implementation. Alongside existing calls to enhance the rigor of research methods (Greenberg \& Harris, 2012; Van dam et al. 2018), we ask whether there is a way to engage in a more versatile research agenda that possibly overcomes dichotomies. Diversifying the ways in which mindfulness in education is studied may begin to convey the richness that the practice seems to hold given its multiple framings (see also, Komjathy, 2018; Owen-Smith, 2017). We suspect that the area of overlap in figure 7 , which reflects the cases of multiple framings of mindfulness (see also 
figure 4), may point in this directions, with qualitative studies of MBIs and quantitative research of contemplative pedagogy. We argue that scholars studying this field need to be more aware of the various framings of mindfulness in this discourse when engaging in its study, so that they might engage in research with a broader perspective on the potential roles that mindfulness may play in education. Novel curricular-pedagogical questions may be generated if we ask for example how do MBIs relate to aspects of mindfulness that tend to remain outside them, such as epistemology and critical pedagogy. Conversely how does contemplative pedagogy relate to mental health?

An additional weakness concerns the paucity of critical papers. The potential concerns with proselytizing appear mostly in popular media but far less in empirical studies (Gregoire, 2013). The theme of adverse effects of mindfulness practice is hardly studied (see Burrows, 2017). Claims that suggest that MBIs may be acclimatizing teachers to an oppressive system are also a cause for concern yet they have not been studied either. We suggest that engaging such questions from multiple research perspective may be crucial for the advancement of this discourse.

Other domains with an obvious potential concern the scarcity of studies at the PreK level. Addressing this domain is not only important for the purpose of understanding mindfulness in this particular age-group; it is also important for considering mindfulness from a longitudinal-developmental perspective. What happens when mindfulness is integrated into curricula from a young age? Is it desirable? Should mindfulness be integrated throughout the public curriculum?

An interesting and broader aspect that began to emerge in this research and calls for future investigation concerns the ways in which the discourse of mindfulness is integrated into other educational discourses merging/supporting/enhancing them. Some examples already lurk behind this research with mindfulness and, SEL (Maloney et al, 2016), the 
scholarship of teaching and learning (Owen-Smith, 2017), self-study in teacher education (Ragoonaden \& Bullock, 2016), critical pedagogy (Hyde \& LaPrad, 2015). The further investigation of these developing integrations open additional possibilities for educational theory and research shedding light both on mindfulness and on the educational fields into which it is integrated.

\section{Limitations}

Our attempt to provide a map of the discourse of mindfulness in education is an ambitious one and not devoid of limitations. We outline three main limitations with the hope that others might address some of them in future work. The first, concerns a critique of our selection criteria. As we noted, prior to this study the reviews in the field were mainly of two kinds: MBI (e.g., Davidson et al., 2012) and contemplative pedagogy reviews (e.g., Bush, 2011). As we indeed found there is no coincidence in this split and this one discourse seems to speak it in various ways. It is hence legitimate to question whether the term mindfulness practice in these two strands applies to the same practice. Some argue that MBIs reflect a very limited aspect of Buddhist mindfulness (Purser \& Milillo, 2015). From this perspective the integrity of the phenomenon under study is challenged. In this paper we followed those who do view these orientations as linked (Hyland, 2015; Repetti, 2016; Roeser, 2013). This by no means implies a relativistic approach in which the label mindfulness applies to any practice as we grounded in previous reviews (Roeser, 2014). Our approach to mindfulness also followed concerns with inclusivity in research acknowledging the ideological and political dimensions that come into play in such endeavours (Wolgemuth et al., 2017). Notwithstanding, there is clearly room for more domain-specific reviews and possibly our broader map may help bring more nuance to them.

A second limitation follows the above in challenging our focus on mindfulness itself, given the possibility of an even more inclusive approach based on the broader category of 
contemplative practices (e.g., yoga). We chose to limit ourselves to the former both for reasons of scope and because at this point there is slightly more clarity as to the boundaries of mindfulness than on the boundaries of what counts as contemplative practices. Nevertheless, we would argue that a study that follows our orientation and explores contemplative practices in general is very much called for and can certainly build on the current one.

The third limitation concerns the actual procedures of selection, coding and categorizing when faced with such huge amounts of data. While we made an effort to be as precise as we could, some cases were more ambiguous. These ambiguities whether applying to inclusion of a paper or coding, were always flagged, discussed and resolved, often with an inclusive approach (i.e., including a paper and applying more than one coding within the same category). It is possible, that in some cases others would have made other choices.

Taking these limitations in mind this research presented a map of the academic discourse of mindfulness in education from 2002 to 2017 revealing its multiple voices as well as its general patterns. This map enables those implementing, studying and/or critiquing mindfulness in education to position their work within a broader context and in relation to strands within this discourse. It also points us to the various ways in which this complex discourse can further develop, hopefully for the benefit of future education. 


\section{References}

Ager, K., Albrecht, N., \& Cohen, M. (2015). Mindfulness in schools research project: exploring students' perspectives of mindfulness-what are students' perspectives of learning mindfulness practices at school?. Psychology, 6(7), 896-914. doi:10.4236/psych.2015.67088

Albrecht, N. (2014). Wellness: a conceptual framework for school-based mindfulness programs. International Journal of Health, Wellness \& Society, 4(1). doi:10.13140/RG.2.2.28103.09120

Ancona, M. R., \& Mendelson, T. (2014). Feasibility and preliminary outcomes of a yoga and mindfulness intervention for school teachers. Advances in School Mental Health Promotion, 7(3), 156-170. doi:10.1080/1754730X.2014.920135

Baer, R. (2015). Ethics, values, virtues, and character strengths in mindfulness-based interventions: a psychological science perspective. Mindfulness, 6(4), 956-969. doi:10.1007/s12671-015-0419-2

Bakosh, L. S., Snow, R. M., Tobias, J. M., Houlihan, J. L., \& Barbosa-Leiker, C. (2016). Maximizing mindful learning: mindful awareness intervention improves elementary school students" quarterly grades. Mindfulness, 7(1), 59-67. doi:10.1007/s12671-0150387-6

Baer, R. A. (2011). Measuring mindfulness. Contemporary Buddhism, 12(01), 241-261.

Bamber, M. D., \& Schneider, J. K. (2016). Mindfulness-based meditation to decrease stress and anxiety in college students: A narrative synthesis of the research. Educational Research Review, 18, 1-32. doi:10.1016/j.edurev.2015.12.004

Beauchemin, J., Hutchins, T. L., \& Patterson, F. (2008). Mindfulness meditation may lessen anxiety, promote social skills, and improve academic performance among adolescents 
with learning disabilities. Complementary Health Practice Review, 13(1), 34-45. doi:10.1177/1533210107311624

Beddoe, A. E., \& Murphy, S. O. (2004). Does mindfulness decrease stress and foster empathy among nursing students?. Journal of Nursing Education, 43(7), 305-312.

Berila, B. (2014). Contemplating the effects of oppression: integrating mindfulness into diversity classrooms. The Journal of Contemplative Inquiry, 1(1), 55-68.

Bishop, S. R., Lau, M., Shapiro, S., Carlson, L., Anderson, N. D., Carmody, J., ... \& Devins, G. (2004). Mindfulness: A proposed operational definition. Clinical psychology: Science and practice, 11(3), 230-241. doi:10.1093/clipsy.bph077

Black, D.S. (2018) Research publications on mindfulness. Retrieved from: https://goamra.org/resources/

Borker, D. R. (2013). Mindfulness practices for accounting and business education: A new perspective. American Journal of Business Education (Online), 6(1), 41.

Boyce, B. (2011). The mindfulness revolution. Boston, MA: Shambhala.

Brown, K. W., Creswell, J. D., \& Ryan, R. M. (Eds.). (2015). Handbook of mindfulness: Theory, research, and practice. New York, NY: Guilford Publications.

Burnett, R. (2011). Mindfulness in schools: Learning lessons from the adults, secular and Buddhist. Buddhist Studies Review, 28, 79-120. doi:10.1558/bsrv.v28i1.79

Burrows, L. (2017). "I feel proud we are moving forward": safeguarding mindfulness for vulnerable student and teacher wellbeing in a community college. The Journal of Adult Protection, 19(1), 33-46. doi:10.1108/JAP-08-2016-0015

Bush, M. (2011). Mindfulness in higher education. Contemporary Buddhism, 12(01), 183197. doi:10.1080/14639947.2011.564838 
Carsley, D., Khoury, B., \& Heath, N. L. (2017). Effectiveness of Mindfulness Interventions for Mental Health in Schools: a Comprehensive Meta-analysis. Mindfulness, 1-15. doi:10.1007/s12671-017-0839-2

Charmaz, K. (2006). Constructing grounded theory: A practical guide through qualitative analysis. London, GB: SAGE.

Corbin, J. M., \& Strauss, A. (1990). Grounded theory research: Procedures, canons, and evaluative criteria. Qualitative sociology, 13(1), 3-21.

Crain, T. L., Schonert-Reichl, K. A., \& Roeser, R. W. (2017). Cultivating teacher mindfulness: Effects of a randomized controlled trial on work, home, and sleep outcomes. Journal of occupational health psychology, 22(2), 138. doi: 10.1037/ocp0000043

Cullen, M. (2011). Mindfulness-based interventions: An emerging phenomenon. Mindfulness, 2(3), 186-193. doi:10.1007/s12671-011-0058-1

Davidson R.J., Dunne J., Eccles J.S., Engle A., Greenberg M., Jennings P.,...\& Vago D. (2012). Contemplative practices and mental training: Prospects for American education. Child Development Perspectives, 6 (2), 146-153. doi:10.1111/j.17508606.2012.00240.x

de Carvalho, J. S., Pinto, A. M., \& Marôco, J. (2017). Results of a mindfulness-based socialemotional learning program on portuguese elementary students and teachers: a quasiexperimental study. Mindfulness, 8(2), 337-350. doi:10.1007/s12671-018-0956-6

DuFon, M. A., \& Christian, J. (2013). The formation and development of the mindful campus. New Directions for Teaching and Learning, 2013(134), 65-72. doi:10.1002/t1.20055

Durlak, J. A., Weissberg, R. P., Dymnicki, A. B., Taylor, R. D., \& Schellinger, K. B. (2011). The impact of enhancing students' social and emotional learning: A meta-analysis of 
school-based universal interventions. Child development, 82(1), 405-432. doi:10.1111/j.1467-8624.2010.01564.x

Erwin, E. J., \& Robinson, K. A. (2016). The joy of being: making way for young children"s natural mindfulness. Early Child Development and Care, 186(2), 268-286. doi:10.1080/03004430.2015.1029468

Felver, J. C., \& Jennings, P. A. (2016). Applications of mindfulness-based interventions in school settings: An introduction, Mindfulness, 7, 1-4. doi:10.1007/s12671-015-0478-4

Flook, L., Goldberg, S. B., Pinger, L., Bonus, K., \& Davidson, R. J. (2013). Mindfulness for teachers: A pilot study to assess effects on stress, burnout, and teaching efficacy. Mind, Brain, and Education, 7(3), 182-195. doi:10.1111/mbe.12026

Flook, L., Smalley, S. L., Kitil, M. J., Galla, B. M., Kaiser-Greenland, S., Locke, J., ... \& Kasari, C. (2010). Effects of mindful awareness practices on executive functions in elementary school children. Journal of applied school psychology, 26(1), 70-95. doi:10.1080/15377900903379125

Forbes, D., (2019). Mindfulness and its discontents. New York: Fernwood publishing

Frank, J. L., Jennings, P. A., \& Greenberg, M. T. (2013). Mindfulness-based interventions in school settings: An introduction to the special issue. Research in Human Development, 10(3), 205-210. doi:10.1080/15427609.2013.818480

Gethin, R. (2011). On some definitions of mindfulness. Contemporary Buddhism, 12(01), 263-279. doi:10.1080/14639947.2011.564843

Glaser B. G., \& Strauss A. L. (1967) The discovery of grounded theory. Strategies for qualitative research. Chicago, IL: Aldine Publishing Company.

Greenberg, M. T., \& Harris, A. R. (2012). Nurturing mindfulness in children and youth: Current state of research. Child Development Perspectives, 6(2), 161-166. doi:10.1111/j.1750-8606.2011.00215.x 
Gregoire, C. (2013). Warstler elementary school in Ohio shuts down mindfulness program due to parent complaints. Retrieved from https://www.huffingtonpost.com/2013/04/17/warstler-elementary-school-ohiomindfulness-program_n_3101741.html

Hanh, T. N. (2016). The miracle of mindfulness: An introduction to the practice of meditation. New York: Beacon Press.

Hart, T. (2004) Opening the contemplative mind in the classroom, Journal of Transformative Education, 2 (1), 28-46. doi:10.1177/1541344603259311

Holland, D. (2004). Integrating mindfulness meditation and somatic awareness into a public educational setting. Journal of Humanistic Psychology, 44(4), 468-484. doi:10.1177/0022167804266100

Hoyt, M. (2016). Teaching with mindfulness: The pedagogy of being-with/for and without being-with/for. Journal of Curriculum Theorizing, 31(1), 126.-142.

Huston, D. C., Garland, E. L., \& Farb, N. A. (2011). Mechanisms of mindfulness in communication training. Journal of Applied Communication Research, 39(4), 406421. doi:10.1080/00909882.2011.608696

Hyde, A. M., LaPrad, J. G. (2015). Mindfulness, Democracy, and Education. Democracy and Education, 23 (2), 2-10.

Hyland, T. (2009). Mindfulness and the therapeutic function of education. Journal of Philosophy of Education, 43(1), 119-131. doi:10.1111/j.1467-9752.2008.00668.x

Hyland, T. (2015). On the contemporary applications of mindfulness: Some implications for education. Journal of Philosophy of Education, 49(2), 170-186. doi:10.1111/14679752.12135

Hyland, T. (2017). McDonaldizing spirituality: mindfulness, education, and consumerism. Journal of Transformative Education, 15 (4), 1-20. doi:10.1177/1541344617696972 
Jennings, P. A. (2016). Mindfulness-based programs and the American public school system: Recommendations for best practices to ensure secularity. Mindfulness, 7(1), 176-178. doi:10.1007/s12671-015-0477-5

Jennings, P. A., \& Greenberg, M. T. (2009). The prosocial classroom: Teacher social and emotional competence in relation to student and classroom outcomes. Review of educational research, 79(1), 491-525. doi:10.3102/0034654308325693

Jennings, P. A., Brown, J. L., Frank, J. L., Doyle, S., Oh, Y., Davis, R., ... \& Greenberg, M. T. (2017). Impacts of the CARE for Teachers program on teachers" social and emotional competence and classroom interactions. Journal of Educational Psychology, 109(7), 1010-1028. doi:10.1037/edu0000187

Kabat-Zinn, J. (1994). Wherever you go, there you are: Mindfulness meditation in everyday life. New York, NY: Hyperion.

Kabat-Zinn, J. (2017). Mindfulness-based stress reduction (MBSR): Authorized curriculum guide. Retreived from: https://www.umassmed.edu/globalassets/center-formindfulness/documents/mbsr-curriculum-guide-2017.pdf

Keng, S. L., Smoski, M. J., \& Robins, C. J. (2011). Effects of mindfulness on psychological health: A review of empirical studies. Clinical psychology review, 31(6), 1041-1056. doi:10.1016/j.cpr.2011.04.006

Kiloran, I. (2017). Mindfulness in education: using and teaching mindfulness in schools, Childhood Education, 93 (2), 99. doi:10.1080/00094056.2017.1300042

Kuyken, W., Weare, K., Ukoumunne, O. C., Vicary, R., Motton, N., Burnett, R., ... \& Huppert, F. (2013). Effectiveness of the Mindfulness in Schools Programme: nonrandomised controlled feasibility study. The British Journal of Psychiatry, 203(2), 126-131. doi:10.1192/bjp.bp.113.126649 
Langer, E. J., \& Moldoveanu, M. (2000). The construct of mindfulness. Journal of social issues, 56(1), 1-9. doi:0.1111/0022-4537.00148

Lawlor, M. S. (2016). Mindfulness and social emotional learning (SEL): A conceptual framework. In Handbook of mindfulness in education (pp. 65-80). New York, NY: Springer. doi:10.1007/978-1-4939-3506-2

Levit-Binnun, N., \& Tarrasch, R. (2014). Relation between contemplative exercises and an enriched psychology students' experience in a neuroscience course. Frontiers in psychology, 5, 1296-1302. doi:10.3389/fpsyg.2014.01296

Lomas, T., Medina, J. C., Ivtzan, I., Rupprecht, S., \& Eiroa-Orosa, F. J. (2017). The impact of mindfulness on the wellbeing and performance of educators: A systematic review of the empirical literature. Teaching and Teacher Education, 61, 132-141. doi:10.1080/1359432X.2017.1308924

Magee, R. V. (2016). The way of ColorInsight: Understanding race and law effectively through mindfulness-based ColorInsight practices. Geo. JL \& Mod. Critical Race Persp., 8, 251-302.

Maloney, J. E., Lawlor, M. S., Schonert-Reichl, K. A., \& Whitehead, J. (2016). A mindfulness-based social and emotional learning curriculum for school-aged children: the MindUP program. In Handbook of mindfulness in education (pp. 313-334). New York, NY: Springer. doi:10.1007/978-1-4939-3506-2

Meiklejohn, J., Phillips, C., Freedman, M. L., Griffin, M. L., Biegel, G., Roach, A., ... \& Isberg, R. (2012). Integrating mindfulness training into K-12 education: Fostering the resilience of teachers and students. Mindfulness, 3(4), 291-307. doi:10.1007/s12671012-0094-5 
Moreno, A. J. (2017). A Theoretically and Ethically Grounded Approach to Mindfulness Practices in the Primary Grades. Childhood Education, 93(2), 100-108. doi:10.1080\%252F00094056.2017.1300487

Mrazek, M. D., Franklin, M. S., Phillips, D. T., Baird, B., \& Schooler, J. W. (2013). Mindfulness training improves working memory capacity and GRE performance while reducing mind wandering. Psychological science, 24(5), 776-781. doi:10.1177/0956797612459659

Napoli, M., \& Bonifas, R. (2011). From theory toward empathic self-care: Creating a mindful classroom for social work students. Social Work Education, 30(6), 635-649. doi:10.1080/02615479.2011.586560

Nelson, D.L. (2012). Implementing mindfulness: Practice as the home of understanding. Paideusis, 20(2), 4-14.

O’Donnell, A. (2015). Contemplative pedagogy and mindfulness: Developing creative attention in an age of distraction. Journal of Philosophy of Education 49(2), 187-202. doi:10.1111/1467-9752.12136

Olendzki, A. (2011). The construction of mindfulness. Contemporary Buddhism, 12(01), 5570. doi:10.1080/14639947.2011.564817

Orr, D. (2002). The uses of mindfulness in anti-oppressive pedagogies: Philosophy and praxis. Canadian Journal of Education/Revue canadienne de l'education, 27(4), 477497. doi: $10.2307 / 1602246$

Owen-Smith, P. (2017). The contemplative mind in the scholarship of teaching and learning. Indianapolis, In: Indiana University Press. doi:10.2307/j.ctt200616w

Perry, T. (2015). Legal fight against yoga in Encinitas is finished. LA Times. Retrieved from http://www.latimes.com/local/lanow/la-me-ln-yoga-legal-fight-20150612-story.html 
Petticrew, M., \& Roberts, H. (2008). Systematic reviews in the social sciences: A practical guide. Malden, MA: John Wiley \& Sons.

Purser, R., \& Loy, D. (2013). Beyond McMindfulness. Huffington post, 1(7). Retrieved from: https://www.huffingtonpost.com/ron-purser/beyond-mcmindfulness_b_3519289.html

Purser, R. E., \& Milillo, J. (2015). Mindfulness revisited: A Buddhist-based conceptualization. Journal of Management Inquiry, 24(1), 3-24. doi:10.1177/1056492614532315

Purser, R. E., Forbes, D., \& Burke, A. (Eds.). (2016). Handbook of mindfulness: Culture, context, and social engagement. Switzerland: Springer. doi:10.1007/978-3-31944019-4.

Ragoonaden, K., \& Bullock, S. (Eds.) (2016). Mindfulness and critical friendship. New York: Lexington books.

Renshaw, T. L., \& Cook, C. R. (2017). Introduction to the special issue: Mindfulness in the schools-historical roots, current status, and future directions, Psychology in the Schools, 54(1), 5-12. doi:10.1002/pits.21978

Repetti, R. (2010). The case for a contemplative philosophy of education. New Directions for Community Colleges, 2010(151), 5-15. doi:10.1002/cc.411

Repetti, R. (2016). Meditation matters: replies to the Anti-McMindfulness bandwagon!. In Handbook of Mindfulness (pp. 473-493). Switzerland, Springer. doi:10.1007/978-3319-44019-4

Reveley, J. (2015). School-based mindfulness training and the economisation of attention: A Stieglerian view. Educational Philosophy and Theory, 47(8), 804-821. doi:10.1080/00131857.2014.914880 
Roeser, R. W. (2013). Mindfulness and human development: A commentary on the special issue. Research in Human Development, 10(3), 273-283. doi:10.1080/15427609.2013.818490

Roeser, R. W., Skinner, E., Beers, J., \& Jennings, P. A. (2012). Mindfulness training and teachers' professional development. Child Development 6(2), 167-173. doi:0.1111/j.1750-8606.2012.00238.x

Rosch, E. (2007). More than mindfulness: When you have a tiger by the tail, let it eat you. Psychological inquiry, 18(4), 258-264.

Roth, H. D. (2006). Contemplative studies: Prospects for a new field. Teacher's College Record, 108 (6), 1787-1815. doi:10.1111/j.1467-9620.2006.00762.x

Schonert-Reichl, K., \& Roeser, R. W. (2016). Handbook of mindfulness in education. New York, NY: Springer. doi:10.1007/978-1-4939-3506-2

Semple, R. J., Droutman, V., \& Reid, B. A. (2017). Mindfulness goes to school: things learned (so far) from research and real-world experiences, Psychology in the Schools, 54(1), 29-52. doi:10.1002/pits.21981

Shapiro, S. L., Lyons, K. E., Miller, R. C., Butler, B., Vieten, C., \& Zelazo, P. D. (2015). Contemplation in the classroom: A new direction for improving childhood education. Educational Psychology Review, 27(1), 1-30. doi:10.1007/s10648-014-9265-3

Shapiro, S., Brown K. W., \& Astin, J. (2011). Toward the Integration of Meditation into Higher Education: A Review of Research Evidence. Teachers College Record 113 (3), 493-528

Singh, N. N., Lancioni, G. E., Karazsia, B. T., Felver, J. C., Myers, R. E., \& Nugent, K. (2016). Effects of Samatha meditation on active academic engagement and math performance of students with attention deficit/hyperactivity disorder. Mindfulness, 7(1), 68-75. doi:10.1007/s12671-015-0424-5 
Steyn, B. J., Steyn, M. H., Maree, D. J., \& Panebianco-Warrens, C. (2016). Psychological skills and mindfulness training effects on the psychological wellbeing of undergraduate music students: an exploratory study. Journal of Psychology in Africa, 26(2), 167-171. doi:10.1080/14330237.2016.1163906

Tarrasch, R. (2017). Mindful schooling: better attention regulation among elementary school children who practice mindfulness as part of their school policy. Journal of Cognitive Enhancement, 1(2), 84-95. doi:10.1007/s41465-017-0024-5

Tarrasch, R., Berman, Z., \& Friedmann, N. (2016). Mindful reading: Mindfulness meditation helps keep readers with Dyslexia and ADHD on the lexical track. Frontiers in psychology, 7, 1-13. doi:10.3389/fpsyg.2016.00578

Tarrasch, R., Margalit-Shalom, L., \& Berger, R. (2017). Enhancing visual perception and motor accuracy among school children through a mindfulness and compassion program. Frontiers in Psychology, 8, 281-299. doi:10.3389/fpsyg.2017.00281

Todd, S. (2015). Experiencing change, encountering the unknown: An education in "negative capability"in light of Buddhism and Levinas. Journal of Philosophy of Education, 49(2), 240-254. doi:10.1002/9781119147305

Van Dam, N. T., van Vugt, M. K., Vago, D. R., Schmalzl, L., Saron, C. D., Olendzki, A., ... \& Fox, K. C. (2018). Mind the hype: A critical evaluation and prescriptive agenda for research on mindfulness and meditation. Perspectives on Psychological Science, 13 (1), 3-27. doi:10.1177/1745691617709589

Weare, K. (2013). Developing mindfulness with children and young people: a review of the evidence and policy context. Journal of Children's Services, 8(2), 141-153.

Webster-Wright, A. (2013). The eye of the storm: A mindful inquiry into reflective practices in higher education. Reflective Practice, 14(4), 556-567. doi:10.1080/14623943.2013.810618 
Wolgemuth, J. R., Hicks, T., \& Agosto, V. (2017). Unpacking assumptions in research synthesis: A critical construct synthesis approach. Educational Researcher, 46(3), 131-139. doi:0.3102/0013189X17703946

Wong, Y. L. R. (2004). Knowing through discomfort: A mindfulness-based critical social work pedagogy. Critical Social Work, 5(1), 1-9.

Wright, L., Gregoski, M. J., Tingen, M. S., Barnes, V. A., \& Treiber, F. A. (2011). Impact of stress reduction interventions on hostility and ambulatory systolic blood pressure in African American adolescents. Journal of Black Psychology, 37(2), 210-233. doi:10.1177/0095798410380203

Zajonc, A. (2013). Contemplative pedagogy: a quiet revolution in higher education. New Directions for Teaching and Learning, 134, 83-94. doi:10.1002/t1.20057

Zenner, C., Herrnleben-Kurz, S., \& Walach, H. (2014). Mindfulness-based interventions in schools - a systematic review and meta-analysis. Frontiers in Psychology, 5, 603-616. doi:10.3389/fpsyg.2014.00603

Zoogman, S., Goldberg, S. B., Hoyt, W. T., \& Miller, L. (2015). Mindfulness interventions with youth: A meta-analysis. Mindfulness, 6(2), 290-302. doi:10.1007/s12671-013$0260-4$ 